\title{
G s. \\ Epstein-Barr virus-driven B cell lymphoma mediated by a unique LMP1-TRAF6 complex
}

\section{Fabian Giehler}

Helmholtz Centre Munich - German Research Centre for Environmental Health, Munich

\section{Michael Ostertag}

Helmholtz Center Munich - German Research Center for Environmental Health

Thomas Sommermann

Max Delbrück Center for Molecular Medicine

\section{Daniel Weidl}

Universitätsklinikum Erlangen, Friedrich-Alexander Universität Erlangen-Nürnberg

\section{Kai Sterz}

Helmholtz Centre Munich - German Research Centre for Environmental Health, Munich

https://orcid.org/0000-0002-7225-0485

\section{Helmut Kutz}

Helmholtz Center Munich - German Research Center for Environmental Health

\section{Stephan Feller}

Weatherall Institute of Molecular Medicine, University of Oxford

\section{Arie Geerlof}

Helmholtz Zentrum München

\section{Brigitte Biesinger}

Institute of Clinical and Molecular Virology, Friedrich-Alexander University Erlangen-Nürnberg

\section{Grzegorz Popowicz}

Helmholtz Zentrum München https://orcid.org/0000-0003-2818-7498

Johannes Kirchmair

University of Vienna, Austria https://orcid.org/0000-0003-2667-5877

\section{Arnd Kieser ( $\square$ a.kieser@helmholtz-muenchen.de )}

Helmholtz Center Munich - German Research Center for Environmental Health https://orcid.org/00000003-0783-1950

\section{Article}

Keywords: Epstein-Barr virus (EBV), latent membrane protein 1 (LMP1), B cell lymphoma, TRAF6, proteinprotein interaction, NF-kB, transformation, in silico structure, NMR spectroscopy, therapeutic target

Posted Date: February 4th, 2022 
DOI: https://doi.org/10.21203/rs.3.rs-1295699/v1

License: (c) (1) This work is licensed under a Creative Commons Attribution 4.0 International License. Read Full License 


\section{Abstract}

The latent membrane protein 1 (LMP1) of Epstein-Barr virus (EBV) drives viral B cell transformation and oncogenesis. LMP1's transforming activity depends on its cytoplasmic C-terminal activation region 2 (CTAR2), which induces NF-KB and JNK by engaging TNF receptor-associated factor 6 (TRAF6). The mechanism of TRAF6 interaction with LMP1 and its critical role for LMP1 signaling has remained elusive. Here we demonstrate that TRAF6 interacts directly with a novel viral TRAF6 binding motif within CTAR2. Structural modeling supported by NMR and functional studies provides insight into the molecular architecture of the LMP1-TRAF6 complex and reveals substantial differences to CD40-TRAF6 interaction. The direct recruitment of TRAF6 to LMP1 is essential for NF-KB activation and survival of LMP1-driven B cell lymphoma. Disruption of the LMP1-TRAF6 complex by inhibitory peptides interferes with proliferation of EBV-transformed B cells. We identify LMP1-TRAF6 as critical virus-host interface and validate this interaction as novel therapeutic target against EBV.

\section{Introduction}

The human gammaherpes virus EBV infects and growth transforms human B cells ${ }^{1,2}$. A global burden of about 143,000 deaths per year is associated with latent EBV infection including cases of Burkitt's lymphoma (BL), Hodgkin's lymphoma ( $\mathrm{HL}$ ), and post-transplant lymphoproliferative disease (PTLD), but also gastric and nasopharyngeal carcinoma (NPC) ${ }^{3}$. Of the viral proteins expressed during latency, only the LMP1 oncoprotein has the potential to transform rodent fibroblasts, and it is essential for viral $B$ cell transformation into lymphoblastoid cell lines (LCLs) ${ }^{4-8}$. Expressed in the B cell compartment of mice, LMP1 causes fatal lymphoma if T cell-mediated immune surveillance is suppressed the same time 9 , 10. LMP1 is expressed in HL, PTLD and NPC, where it critically contributes to pathogenesis ${ }^{1,11}$.

LMP1 is a transmembrane protein of 386 amino acids, which consists of a short N-terminus, six transmembrane domains and a C-terminal cytoplasmic signaling domain ${ }^{12}$. By spontaneous clustering in the membrane LMP1 mimics a constitutively active receptor of the tumor necrosis factor (TNF) receptor family 7,13 . Essential for cell transformation by LMP1 are the C-terminal activation regions (CTAR) 1 and 2, which reside within the signaling domain ${ }^{12}$. Individual inactivation of either region massively diminishes the transforming potential of EBV in primary $\mathrm{B}$ cells ${ }^{8}$.

CTAR1 directly recruits the TNF receptor-associated factor (TRAF) family members TRAF1, 2, and 3 via its TRAF-binding consensus motif $\mathrm{P}_{204} \times \mathrm{X} \times \mathrm{T}$ to induce non-canonical and atypical NF-KB signaling, phosphoinositide 3-kinase (PI3K), and the mitogen-activated protein kinase (MAPK) pathways ERK and p38 (Figure 1A) ${ }^{14-20}$. Further, presumably indirect recruitment of TRAF5 and TRAF6 to CTAR1 has been reported ${ }^{17,21}$. In the presence of high TRAF1 levels, CTAR1 also contributes to canonical NF-KB and cJun N-terminal kinase (JNK) activation ${ }^{22-26}$. 
CTAR2, the major activation site of canonical NF-KB, JNK, p38, and interferon regulatory factor 7 (IRF7), recruits TRAF6 as the critical signaling mediator for all known CTAR2-induced pathways ${ }^{12,19,21,27-30}$. TRAF6 bridges CTAR2 with the downstream mediators TNIK (TRAF2 and NCK-interacting protein kinase), TAK1 (transforming growth factor $\beta$-activated kinase 1), TAB1/2 (TGF $\beta$-activated kinase 1 binding protein $1 / 2$ ), the IKK (IKB kinase) complex, and LIMD1 (LIM domain-containing protein 1) ${ }^{31-34}$. In contrast to the TNF-receptor-associated death domain protein (TRADD), which binds to the sixteen C-terminal amino acids of CTAR2 and is involved in NF-KB signaling by LMP1, the mechanism of TRAF6 recruitment and, thus, the molecular basis for its essential role in LMP1 signaling has remained unknown ${ }^{30,35-38}$.

The sequence $\mathrm{P}_{379}$ VQLSY ${ }_{384}$, located at the C-terminus of CTAR2, is responsible for NF-KB and JNK activation by CTAR2 (Figure 1A) ${ }^{37,39}$. Although this sequence includes the putative TRAF1/2/3 binding motif PxQxS ${ }^{40}$, direct physical interaction of CTAR2 with TRAF molecules has never been demonstrated. One study suggested that TRAF6 recruitment to CTAR2 might be indirect, possibly mediated by the transcription factor BS69 ${ }^{41}$.

The TRAF protein family consists of seven members, TRAF1 to 7. Of these seven isoforms, TRAF1 to 6 share the so-called TRAF domain, which is located at the C-terminus of the TRAF molecule and is composed of a TRAF-N (or coiled-coil) domain, and a TRAF-C domain, the latter built of seven to eight anti-parallel $\beta$-strand folds ${ }^{42,43}$. Mediated by their TRAF domains, TRAF proteins form mushroom-like trimers, which can interact with receptors through TRAF-C ${ }^{43-45}$. The TRAF domain of TRAF6 is sufficient to mediate TRAF6 interaction with the LMP1 complex ${ }^{19}$. TRAF6 lacking its TRAF domain is unable to rescue TRAF6 deficiency in LMP1 signaling, further supporting a role of this domain for interaction with LMP1 ${ }^{21}$. The N-terminal RING finger of TRAF6 possesses E3 lysine 63 (K63)-linked ubiquitin ligase activity, which plays an important role in activation of LMP1 downstream signaling including TAK1 and IKK $\beta$ activation ${ }^{12,46}$.

LMP1 mimics signals of the co-stimulatory receptor CD40 during B cell proliferation and can largely replace $C D 40$ functions in vivo ${ }^{7,47-49}$. TRAF6 deficiency affects $B$ cell numbers driven by a conditional CD40-LMP1 fusion protein in the lymph nodes of mice ${ }^{50}$. However, a potential role of TRAF6 in LMP1dependent lymphoma has not been demonstrated. Although both, LMP1 and CD40, engage TRAF6 for signaling, the underlying molecular mechanisms seem to differ. CD40 carries two major TRAF binding sites, a TRAF1/2/3 binding site with the sequence $P_{250}$ VQET, and the TRAF6 interaction site $\mathrm{Q}_{231} \mathrm{EPQ}_{235} \mathrm{EINF} 51,52$. The TRAF binding sites of $\mathrm{CD} 40$ are largely redundant with respect to their functions in NF-KB and JNK activation in $B$ cells ${ }^{53}$. At the molecular level, JNK signaling induced by LMP1 differs from CD40 with respect to the functions of IKK $\beta$ and TPL2 ${ }^{34,54}$.

In the present study, we characterize the interaction between LMP1 and TRAF6 as novel virus-host interface, which is based on direct protein-protein interaction. We provide structural insight into the molecular architecture of the LMP1-TRAF6 complex, and demonstrate that the direct interaction of LMP1 and TRAF6 is critical for LMP1 function and the survival of EBV-transformed B cells. In summary, we 
reveal the molecular mechanism of TRAF6 engagement by LMP1 for signaling and lymphoma development.

\section{Results}

\section{TRAF6 interacts directly with $\mathrm{P}_{379} \mathrm{VQLSY}_{384}$ of LMP1}

We examined all TRAF proteins involved in LMP1 signaling regarding their potential to directly bind to the LMP1 signaling domain (Figures 1A and 1B, Supplementary Figure 1A). The purified recombinant TRAF domains of TRAF1, 2, 3, and 5 interacted with $\mathrm{P}_{204}$ QQAT of CTAR1 in pull-down assays with glutathione S-transferase (GST)-coupled LMP1 $1_{181-386}$ (Figure 1B). Mutation of $\mathrm{P}_{204} \times \mathrm{XQXT}$ into $\mathrm{A}_{204} \mathrm{XAxA}$ abolished LMP1 binding of TRAF1, 2, and 5. Residual amounts of TRAF3 were recruited by the $A_{204} X A X A$ mutant, which can be explained by contacts of TRAF3 with LMP1 residues adjacent to the $\mathrm{P}_{204} \times \mathrm{X} \times \mathrm{T}$ core motif 55 .

Investigating the interaction between LMP1 and TRAF6 we made the surprising observation that also recombinant His-TRAF6 ${ }_{310-522}$, which includes the TRAF domain of TRAF6, was efficiently recruited by GST-LMP1 (Figure 1B). In contrast to all other TRAF proteins tested, TRAF6 recruitment to LMP1 was not affected by mutation of CTAR1, but was eliminated by the exchange of tyrosine 384 into glycine. In accordance with this finding, Flag-TRAF6 wildtype only co-immunoprecipitated with HA-LMP1 from HEK293 cells if CTAR2 was intact (Supplementary Figure 1B). These experiments provided the first evidence for a direct protein-protein interaction as the molecular basis of TRAF6 recruitment to LMP1.

To further substantiate this result and to narrow down the LMP1 sequences involved in LMP1-TRAF6 interaction, we tested the ability of His-TRAF6 ${ }_{310-522}$ to interact with immobilized LMP1-derived peptides, which incorporate CTAR1 or CTAR2 sequences (Figure 1C and Supplementary Figure 1C). Recombinant His-TRAF2 $311-501$ was used as control. Specificity of TRAF interaction was confirmed by including peptides, which harbored alanine exchanges within the TRAF2-binding motifs of CD40 ( $\mathrm{P}_{250} \mathrm{VQET}$ to $\mathrm{A}_{250}$ VAEA, peptides 1 and 2, respectively), LMP1 ( $\mathrm{P}_{204} \mathrm{QQAT}$ to $\mathrm{A}_{204} \mathrm{QAAA}$, peptides 6 and 7 ), and the TRAF6 binding motif of $C D 40\left(Q_{231}\right.$ EPQEINF to $A_{231}$ EAQAINF, peptides 1 and 3$)$. CD40-derived amino acids 244-273 lacked the TRAF6 binding site (peptide 4). Additional mutation of the TRAF2-binding motif within peptide 4 resulted in peptide 5 . We have shown previously that amino acids 371-386 of LMP1 are sufficient to induce TRAF6-dependent CTAR2 signaling ${ }^{30}$. To determine whether these sixteen amino acids contain the complete TRAF6 binding site of LMP1, they were included as peptide 8 . Within peptide $8, Y_{384}$ and $Y_{385}$, or the cryptic TRAF interaction motif $P_{379} x Q x S$ were mutated (peptides 9 and 10 , respectively). Further, CTAR2 amino acids 357-386 were spotted (peptide 11), in which $P_{379} \times Q x S$ was mutated (peptide 12).

Both TRAF2 and TRAF6 specifically interacted with their designated binding sites within CD40, confirming accuracy of the peptide array (Figure 1C). Further, TRAF2 bound to $\mathrm{P}_{204}$ QQAT of CTAR1 
(peptides 6 and 7), but not to CTAR2 (peptides 8 to 12), which excludes the possibility of direct TRAF2 interaction with the cryptic TRAF interaction motif of CTAR2. Notably however, TRAF6 was efficiently captured by the CTAR2 peptides 8 (16mer) and 11 (30mer), whereas it did not bind to CTAR1 (peptide 6). Mutation of $Y_{384}$ and $Y_{385}$ to $A A$ (peptide 9) and $P_{379} \times Q \times S$ to AxAxA (peptides 10 and 12) abolished direct TRAF6 binding to CTAR2 (Figure 1C).

We performed an alanine exchange mutagenesis scan from $\mathrm{G}_{378}$ to $\mathrm{Y}_{385}$ of LMP1 to precisely map the residues that are involved in TRAF6 binding. We developed a highly reliable mix-and-measure screening assay for the LMP1-TRAF6 interaction based upon the Perkin-Elmer AlphaScreen technology, by which the effects of mutations on this protein-protein interaction (PPI) can be detected and quantified directly (Figure 1D). Light emission at 520-620 nm is directly proportional to the affinity of the two protein components of the assay. Each of the LMP1 amino acids $P_{379}, V_{380}, Q_{381}$ and $Y_{384}$ was essential for direct TRAF6 recruitment to the LMP1 signaling domain (Figure 1E). Mutation of $Y_{385}$ had only minor impact on TRAF6 binding at the lowest TRAF6 concentration tested in the assay (100 nM), whereas the side chains of $G_{378}, L_{382}$ and $S_{383}$ were dispensable for interaction. Of note, the resulting TRAF6 binding sequence $P_{379} V Q x x Y$ exactly matches the NF-KB- and JNK-inducing region of CTAR2 ${ }^{37,39}$. This finding strongly suggested that the direct binding of TRAF6 to this sequence is in fact the molecular basis for CTAR2 signaling.

TRAF6 showed a weaker affinity for LMP1 as compared to CD40. The $\mathrm{K}_{\mathrm{D}}$ of His-TRAF6 $310-522$ interaction with GST-CD40 was $17.8 \pm 4 \mathrm{nM}$ in contrast to $77.1 \pm 21.7 \mathrm{nM}$ with GST-LMP1, determined by the AlphaScreen PPI assay (Figure 1F). Confirming our previous data, mutation of LMP1 $\mathrm{P}_{379} \times Q \times x Y$ into $A_{379} \times A x x A$ abolished TRAF6 binding. Analogous mutation of the TRAF6 binding motif within CD40, which was included as control, resulted in a loss of TRAF6 interaction as well (Figure 1F).

Alignment of the consensus TRAF6 interaction motif PxExxF/Y/D/E of cellular receptors ${ }^{45,51}$ with the newly identified TRAF6 binding sequence of LMP1 revealed high similarity, with the exception of one striking difference at the central position $P_{0}$ (Figure 1F). Cellular TRAF6-recruiting sequences carry a glutamic acid at $\mathrm{P}_{0}{ }^{45,56-58}$, whereas this position is occupied by glutamine in LMP1. Remarkably, glutamic acid at $\mathrm{P}_{0}$ of the TRAF6 binding motif of CD40 cannot be replaced by any other amino acid, including glutamine, without losing affinity to TRAF ${ }^{56}$. We tested the effect of converting the TRAF6 binding motif of LMP1 into the cellular consensus motif by $Q_{381} E$ mutation. The resulting LMP1 $Q_{381} E$ mutant is capable of binding TRAF6 with significantly enhanced affinity as compared to wildtype LMP1 (Figure 1G, compare to GST-LMP1 wildtype of Figure 1F). $Q_{381} E$ mutation reduced the $K_{D}$ from $77.1 \pm$ $21.7 \mathrm{nM}$ to $8.1 \pm 0.9 \mathrm{nM}$, which is even lower as the $K_{D}$ of TRAF6 interaction with CD40. This may suggest that additional interactions of TRAF6 with LMP1 beyond $\mathrm{P}_{0}$, which are absent in the CD40-TRAF6 complex, stabilize LMP1 interaction with TRAF6 and allow $\mathrm{P}_{0}$ being occupied by glutamine. 
Position $\mathrm{P}_{3}$ of LMP1's TRAF6-binding motif is filled by $\mathrm{Y}_{384}$, which has a critical role in LMP1 signaling and viral cell transformation ${ }^{8,19,37,39}$. In cellular TRAF6-interacting receptors this position can be occupied by an aromatic or acidic amino acid ${ }^{45}$. Accordingly, a permutation scan at $\mathrm{P}_{3}$ of CD40 showed that TRAF6 binding to CD40 still occurs if $\mathrm{F}_{238}$ is mutated into tyrosine or tryptophan ${ }^{51}$. To test variability at the $P_{3}$ position of LMP1, we introduced a $Y_{384} F$ mutation resembling $P_{3}$ of the TRAF6 binding motif of CD40. The $Y_{384} F$ exchange was not only tolerated by LMP1, but even improved the affinity of LMP1 to TRAF6 (Figure 1G). As expected, $Q_{381} A$ and $Y_{384} A$ exchanges abolished TRAF6 binding (Figure 1G). Taken together, TRAF6 is directly recruited by the JNK- and NF-KB-inducing sequence $\mathrm{P}_{379}$ VQLSY within CTAR2 and is, thus, the first identified cellular factor whose binding site exactly matches the signalingactive site of CTAR2. In contrast to cellular receptors, this motif contains glutamine at the central $P_{0}$ position, likely facilitated by unique structural characteristics of the viral LMP1-TRAF6 complex.

\section{Arginine 392 of TRAF6 discriminates between LMP1 and CD40}

To examine whether LMP1 binds to the same region at the surface of TRAF6 as cellular receptors, we mutated amino acids within TRAF6 that are involved in interaction with $\mathrm{P}_{-2}, \mathrm{P}_{0}$, or $\mathrm{P}_{3}$ of $C D 40$ and receptor activator of NF-KB (RANK, also known as TRANCE receptor) ${ }^{45}$. The capability of the TRAF6 mutants $R_{392} A, K_{469} A, F_{471} A$, or $Y_{473} A$ to bind to GST-LMP1 or GST-CD40 was analysed in AlphaScreen PPI experiments (Figure 2A). $F_{471}$ and $Y_{473}$ of TRAF6 build the binding pocket for amino acid $P_{-2}$ of cellular receptors ${ }^{45,58}$. $F_{471} A$ or $Y_{473} A$ mutation caused a complete loss of TRAF6 binding to LMP1, as to CD40 (Figure 2A). Hence, this pocket forms an essential interaction with LMP1, most probably with LMP1 residue $P_{379}$, which occupies $P_{-2}$ of the $P_{379} V Q x x Y$ motif. Mutation of $K_{469}$ into alanine had no effect on TRAF6 interaction with LMP1 or CD40. The side chain of $\mathrm{K}_{469}$ likely forms non-essential charge-charge interactions with the main chain carboxylate of $\mathrm{P}_{0}$ of $\mathrm{CD} 40{ }^{45}$.

The TRAF6 mutant $R_{392} A$ revealed a striking difference regarding LMP1 and CD40 binding. $R_{392}$ forms an amino-aromatic interaction with $\mathrm{F}_{238}$ at $\mathrm{P}_{3}$ of $\mathrm{CD} 40{ }^{45}$. However, mutation of $\mathrm{R}_{392}$ into alanine had no impact on TRAF6 binding to CD40, whereas interaction with LMP1 was fully eliminated by this mutation (Figure 2A). $R_{392}$ thus discriminates between LMP1 and CD40. This result suggested a different molecular architecture of the LMP1-TRAF6 complex as compared to CD40-TRAF6.

To verify the relevance of our findings on LMP1-TRAF6 interaction in vivo, we expressed Flag-tagged TRAF6 wildtype or the mutants $R_{392} A, K_{469} A, F_{471} A$ and $Y_{473} A$ together with HA-tagged LMP1 in HEK293 cells and performed co-immunoprecipitations of both proteins (Figure 2B and Supplementary Figure 2A). Confirming our previous results, each of the mutations $R_{392} A, F_{471} A$ or $Y_{473} A$, abolished TRAF6 interaction with $L M P 1$, whereas $\mathrm{K}_{469} \mathrm{~A}$ mutation had no negative effect on the interaction between both proteins in HEK293 cells. Confocal immunofluorescence studies in HeLa cells further verified these results (Figure $2 \mathrm{C}$ ). Flag-TRAF6 wildtype and the $\mathrm{K}_{469} \mathrm{~A}$ mutant co-located to a high extent with HA-LMP1 
clusters, demonstrating their interaction with LMP1 in situ. In contrast, the TRAF6 mutants $R_{392} A, F_{471} A$ and $\mathrm{Y}_{473} \mathrm{~A}$ showed a strongly decreased co-localization with HA-LMP1, which was comparable to the LMP1 $\triangle$ 371-386 mutant lacking the TRAF6 interaction site (Figure $2 \mathrm{C}$ and Supplementary Figure 2B). In the absence of LMP1, all TRAF6 mutants showed a similar cytoplasmic distribution as TRAF6 wildtype (Supplementary Figure 2C). In summary, these results demonstrated that binding of TRAF6 to LMP1 involves the same TRAF6 residues in the cellular context as in our interaction studies with recombinant proteins, which strongly argues for the same and direct mechanism of LMP1-TRAF6 complex formation in vivo as in vitro.

\section{Direct binding of TRAF6 to LMP1 is required for CTAR2 signaling}

CTAR2 signaling is defective in TRAF6-deficient mouse embryonic fibroblasts (MEFs) and can be rescued by exogenous TRAF6 expression 19, 27, 28, 30. To demonstrate that direct interaction of LMP1 and TRAF6 is indeed the molecular basis for CTAR2 signaling, we tested the TRAF6 mutants that are defective in direct LMP1 binding for their potential to rescue CTAR2 signaling in NF-KB reporter assays in TRAF6-/- MEFs (Figure 3A). TRAF6-/- cells were transfected with the CTAR1 mutant $\mathrm{A}_{204} \mathrm{XAxA}$, which signals towards NF$\mathrm{KB}$ only through CTAR2, or the inactive double mutant $\mathrm{A}_{204} \mathrm{XAxA} / \triangle 371-386$, together with wildtype TRAF6 or the TRAF6 mutants $R_{392} A, F_{471} A$ and $Y_{473} A$. Comparable protein expression levels were confirmed by immunoblot analysis (Supplementary Figure 3A). In the absence of TRAF6, CTAR2 was unable to induce NF-kB reporter activity (Figure 3A, see w/o). As expected, expression of wildtype TRAF6 or the TRAF6 mutants alone (co-transfection with inactive $A_{204} \times A x A / \Delta 371-386$ ) induced NF-KB to similar levels (grey bars), demonstrating that all mutants fully retained their downstream signaling capacity. However, only TRAF6 wildtype, but none of the binding-defective mutants, was able to rescue CTAR2 signaling to NF-KB (green bars). This result showed that the direct interaction of TRAF6 with LMP1 is critical for activation of CTAR2-mediated NF-KB signaling.

To further confirm this result, we retrovirally transduced TRAF6-/- MEFs, which stably express NGFRLMP1, with TRAF6 wildtype or the TRAF6 mutants $R_{392} A, F_{471} A$ and $Y_{473} A$. NGFR-LMP1 is a fusion construct of the extracellular and transmembrane domains of the p75 nerve growth factor (NGF) receptor (NGFR) with the intracellular signaling domain of LMP1 ${ }^{13,34}$. Instant NGFR-LMP1 activity can be triggered at the cell surface by incubation of the cells with an a-NGFR primary antibody and subsequent crosslinking by a secondary antibody (Figure 3B). Antibody crosslinking of NGFR-LMP1 caused a rapid degradation of $\mathrm{IKBa}$, which is indicative for activation of the canonical NF-KB pathway in wildtype MEFs (Supplementary Figure 3B and ref. $34^{34}$ ). In TRAF6-/- cells this pathway was defective (Supplementary Figure 3B). Exogenous expression of TRAF6 wildtype in TRAF6-/- cells restored activation of the canonical NF-KB pathway upon NGFR-LMP1 crosslinking (Figure 3C). In contrast, the TRAF6 mutants $R_{392} A, F_{471} A$ and $Y_{473} A$, which are unable to directly bind to $L M P 1$, were also ineffective in rescuing canonical NF-KB activation by CTAR2 (Figure 3C). Taken together, our data demonstrated that CTAR2 only induces NF-KB if TRAF6 is directly recruited to CTAR2. 


\section{Molecular model of the LMP1-TRAF6 complex}

Our experiments with the TRAF6 mutant proteins showed that LMP1 binds to the same PPI interface of TRAF6 as CD40 and other cellular receptors. To gain structural insights into the binding of TRAF6 to LMP1, we used Molecular Operating Environment to derive an in silico model of the LMP1-TRAF6 complex (Figure 4A). The sequence alignment between LMP1 and TRAF6-binding receptor peptides (see Figure 1F) showed no indication for significant structural differences in the proximity of position $\mathrm{P}_{-2}$ between LMP1 and cellular receptors, because this position is always occupied by a proline. Accordingly, $P_{397}$ of LMP1 is located in the hydrophobic indentation formed primarily by TRAF6 residues $M_{450}, F_{471}$ and $Y_{473}$ (Figure $4 A$ ). In line with this finding, mutation of the TRAF6 residues $F_{471}$ and $Y_{473}$ abolished LMP1 binding (see Figure 2).

At $\mathrm{P}_{-1}$ of LMP1, hydrogen bonds are formed between the main chain of $\mathrm{V}_{380}$ and the main chain of TRAF6 residue $G_{472}$. The loss of TRAF6 binding of the LMP1 mutant $V_{380} A$ might be related to a loss of surface contacts between the side chains of LMP1 $\mathrm{V}_{380}$ and TRAF6 $\mathrm{V}_{474}$.

The most significant difference between LMP1 and the consensus TRAF6-binding sequence $\mathrm{PxExxF/Y/D/E}$ is that in cellular receptors $\mathrm{P}_{0}$ is occupied with glutamic acid, while LMP1 carries a glutamine at this position. Even more, an exchange of glutamic acid by glutamine is not tolerated at $\mathrm{P}_{0}$ of CD40 ${ }^{56}$. For cellular receptors it has been shown that the side chain carboxylate of glutamic acid at $P_{0}$ forms a strong hydrogen bond network with the backbone amide nitrogen atoms of $L_{457}$ and $A_{458}{ }^{45,58}$. Also in our LMP1-TRAF6 model, hydrogen bonds are formed between $\mathrm{Q}_{381}$ at $\mathrm{P}_{0}$ of LMP1 and the amide $\mathrm{NH}$ atoms of $\mathrm{L}_{457}$ and $\mathrm{A}_{458}$ of TRAF6 (Figure 4B). Yet, due to the different charge of the side chains, the strength of $\mathrm{Q}_{381}$ interaction with TRAF6 is weaker compared to $\mathrm{E}_{235}$ of CD40 with TRAF6. Accordingly, the $\mathrm{Q}_{381} \mathrm{E}$ exchange significantly increases the affinity between LMP1 and TRAF6 (see Figure 1F).

Mutation of $L_{382}$ at $P_{1}$ to alanine does not impair LMP1-TRAF6 binding. This is consistent with the model, which indicates that hydrogen bonds at this position are formed by the peptide backbone with the TRAF6 residues $G_{470}$ and $R_{392}$ and are hence invariant to changes of the side chain (Figure $4 C$ ). In addition, $R_{392}$ forms another hydrogen bond with $S_{383}$ at $P_{2}$ of the LMP1 main chain. These interactions explain the critical role of $R_{392}$ for TRAF6 interaction with LMP1. When TRAF6 binds to CD40, $R_{392}$ adopts a different conformation and forms a hydrophobic pocket for $\mathrm{F}_{238}$ at $\mathrm{P}_{3}{ }^{45}$. The main chain carbonyl at $\mathrm{P}_{2}$ of CD40 is, thus, not within hydrogen bonding distance to $R_{392}$. Whereas the side chain of $F_{238}$ of CD40 shows a kinked orientation towards TRAF6, $\mathrm{Y}_{384}$ of LMP1 adopts a rather stretched conformation along the surface of TRAF6. This orientation enables $\mathrm{Y}_{384}$ at $\mathrm{P}_{3}$ of LMP1 to build non-polar surface contacts with $R_{392}$ and $V_{374}$ of TRAF6 over a large area. Taken together, the unique conformation of the LMP1-TRAF6 interface at $P_{1}$ to $P_{3}$ enables additional stabilizing contacts between LMP1 and TRAF6, which are not present in CD40-TRAF6, and may well explain why LMP1 tolerates glutamine at $P_{0}$. 


\section{NMR spectroscopy reveals shifting of TRAF6 residues upon LMP1 binding}

To confirm the binding position of LMP1 at TRAF6 proposed by our biochemical and modeling data, we recorded NMR spectra of TRAF6 in its free form as well as bound to the LMP1 peptide $G_{378}$ PVQLSYYD (Figure 5A). Addition of the peptide caused significant shifts as well as line broadening in some peaks in the TRAF6 spectra, a clear indication of binding. Based on a previously published partial backbone chemical shift assignment of TRAF6 ${ }^{59}$, several TRAF6 residues of interest could be assigned to peaks in the recorded spectra. Of those TRAF6 residues previously tested for their functions in LMP1 binding (see Figures 2 and 3), $F_{471}$ and $K_{469}$ are highlighted in both spectra $\left(R_{392}\right.$ and $Y_{473}$ have not been assigned by

Moriya and colleagues ${ }^{59}$ ). Upon addition of the LMP1 peptide, the peaks corresponding to these residues are broadened beyond detection, indicating that these residues contribute strongly to binding. Because mutation of $\mathrm{K}_{469}$ had no effect on LMP1 interaction, this result supports a role of the $\mathrm{K}_{469}$ backbone in LMP1 binding. Next, the chemical shift pattern caused by the LMP1 peptide was calculated and plotted onto the modeled LMP1-TRAF6 complex (see Figure 4). The overall assigned shift perturbations caused by the addition of LMP1 peptide are clustered around the TRAF6 PPI surface and confirmed LMP1 binding at this position (Figure 5B).

\section{LMP1-driven B lymphomas are strictly dependent on TRAF6}

CTAR2 provides critical signals for effective growth transformation of primary B cells by EBV 8, 60 . Because we showed that direct TRAF6 interaction with CTAR2 is required for CTAR2 signaling we next asked whether TRAF6 is necessary for proliferation and survival of LMP1-driven B cell lymphomas. To address this question, TRAF6 was targeted by an ex vivo CRISPR/Cas9 approach in the two LMP1dependent $B$ cell lymphomas LMP1-CL 37 and 40 derived from the transgenic CD19-

Cre,R26LMP1 ${ }^{\text {stopfl: }} C D 3 \varepsilon^{K O}$ mouse model ${ }^{9,61}$. The effect of three different gRNAs targeting the gene of interest (GOI) TRAF6 on tumor cell survival was examined. gRNAs targeting LMP1 as positive or the intracellular adhesion molecule 1 (ICAM1) as negative controls were included in parallel transfections. Cell survival was monitored seven days post transfection as selection score of the gRNAs targeting the GOI versus a non-targeting (NT) gRNA directed against an irrelevant Rosa26 sequence (Figure 6A and Methods).

The knockout of LMP1 resulted in a drastic reduction of survival of the LMP1-CL 37 and 40 lymphomas (Figure 6B and 6C). This result was expected because both lymphomas had been selected for their dependence on LMP1 ${ }^{61}$ (see Methods). In contrast, targeting of ICAM1 did not affect lymphoma survival. More interestingly, we found that inactivation of TRAF6 by CRISPR/Cas9 caused a massive negative effect on lymphoma survival, which was comparable to the effect of LMP1 targeting itself (Figure 6B and $6 \mathrm{C})$. Hence, both lymphomas are absolutely dependent on TRAF6, demonstrating a previously unappreciated critical role of TRAF6 in the survival of LMP1-dependent B lymphoma cells. These findings 
further suggested that the direct interaction between LMP1 and TRAF6 is an important factor for lymphoma development and may serve as a novel therapeutic target for inhibitory molecules.

\section{Disruption of the LMP1-TRAF6 complex interferes with lymphoblastoid cell survival}

We showed so far that the direct interaction of TRAF6 with LMP1 is required for CTAR2 signaling, and that TRAF6 has an important function in mediating survival of LMP1-driven B cell lymphomas. To prove that the direct LMP1-TRAF6 complex can be targeted in vivo, we aimed to inhibit TRAF6 recruitment to LMP1 by peptides to test the effect of LMP1-TRAF6 PPI disruption on LCL survival. Previously, cellpenetrating TRAF6 inhibitory peptides derived from the TRAF6 binding site of RANK had been used to inhibit receptor interaction of TRAF6 and RANK signaling 45, 62,63. The RANK sequence RKIPTEDEY contains the motif PxExxY that binds to the same site of TRAF6 as CD40 ${ }^{45}$. Because LMP1 also interacts with this region at the TRAF6 surface, we reasoned that the RANK-derived peptide should be able to block TRAF6 interaction with LMP1. An alignment of the TRAF6 inhibitory peptide with CD40 and LMP1 sequences is shown in Figure 7A. We used a cell-penetrating version of this peptide, fused to the Antennapedia leader sequence, to inhibit TRAF6 interaction with LMP1. A peptide containing the leader sequence only served as negative control.

Indeed, the TRAF6 inhibitor peptide blocked interaction of TRAF6 and GST-LMP1 in AlphaScreen PPI assays with an $\mathrm{IC}_{50}$ of $177 \mathrm{nM}$, while the control peptide was inactive (Figure 7B). TRAF6 binding to GSTLMP1 wildtype and the $A_{379} \times A x x A$ null mutant demonstrated the dynamic range of the assay and verified that LMP1-TRAF6 inhibition by the peptide was complete (Figure 7B). As expected, the inhibitor peptide had no effect on the recruitment of TRAF2 to LMP1 (Figure 7C). TRAF6 binding to CD40 was inhibited by the peptide as well, albeit with strongly reduced efficiency as compared to LMP1 (Figure 7D).

Finally, we examined the TRAF6 inhibitor peptide for its effects on LCL viability. Two lymphoblastoid cell lines, LCL721 and HA-LCL3, were incubated for three days in the presence of the TRAF6 inhibitor peptide or the control peptide, respectively. The EBV-negative Burkitt's lymphoma cell line BL41 was included as negative control (Figure 7E). The TRAF6 inhibitor peptide, but not the control peptide, caused a severe reduction of cell viability in both LMP1-dependent LCLs, whereas no such effect was seen in LMP1independent BL41 cells. This result corroborated our previous results regarding the relevance of TRAF6 function for the survival of EBV/LMP1-transformed cells. It further showed that the direct interaction of TRAF6 with LMP1 is essential for LMP1's pro-survival function and might therefore constitute a novel therapeutic target for inhibitors, for instance small molecule LMP1-TRAF6 PPI inhibitors.

\section{Discussion}

With this study we finally answer the long-standing open question how the signaling-active sequence $\mathrm{P}_{379}$ VQLSY of LMP1 and its signaling mediator TRAF6 are connected at the molecular level. We demonstrate a direct protein-protein interaction of LMP1 and TRAF6 that is critical for both, CTAR2 signaling and the survival of LMP1-transformed B cells. The viral TRAF6 binding motif PVQxxY is unique 
compared to known cellular TRAF6 binding motifs because it carries glutamine instead of glutamic acid at $P_{0}$. Interestingly, it was shown previously that an exchange of glutamic acid to glutamine at $P_{0}$ is not tolerated in CD40 without losing affinity to TRAF6 ${ }^{56}$. The stabilizing interactions of LMP1 $P_{1}$ to $P_{3}$ with $R_{392}$ of TRAF6 are enabled by the different spacial orientation of $Y_{384}$ as compared to $F_{238}$ of CD40, and may explain why the Q-E exchange at $P_{0}$ is tolerated by LMP1, but not CD40. However, LMP1 wildtype shows weaker affinity to TRAF6 than CD40, which might constitute an important mechanism of balancing the signaling strength of constitutively active LMP1 within limits that are supportive for cell survival. Highly elevated LMP1 signaling levels have been shown to induce cytostasis or even cell death 12 .

Our results explain the earlier observation that mutation of LMP1 $\mathrm{Y}_{384} \mathrm{YD}$ into $\mathrm{F}_{384} \mathrm{FD}$ preserves LMP1's capacity of mediating CTAR2-dependent NF-KB signaling, whereas mutation into $\mathrm{I}_{384} \mathrm{D}$ abolishes LMP1 activity ${ }^{36}$. The $\mathrm{Y}_{384} \mathrm{~F}$ exchange at $\mathrm{P}_{3}$ maintains a functional TRAF6 interaction motif, with a decent $K_{D}$ of TRAF6 interaction (see Figure $1 \mathrm{G}$ ). In contrast, $\mathrm{I}_{384} \mathrm{D}$ mutation is expected to destroy the TRAF6 binding motif. Accordingly, $F_{384} \mathrm{FD}$, but not $\mathrm{I}_{384} \mathrm{D}$, supports $\mathrm{B}$ cell transformation ${ }^{36}$, which further underscores the relevance of the TRAF6 interaction motif and, thus, TRAF6 for the transforming capacity of LMP1.

Although the presence of LMP1 and TRAF6 in one signaling complex has been observed previously, direct interaction of both molecules was not reported ${ }^{19,31,35}$. It was suggested that TRAF6 is recruited to CTAR2 by an indirect mechanism involving TRADD or BS69 ${ }^{19}$, 41 . We now show that direct interaction of TRAF6 with $\mathrm{P}_{379}$ VQLSY is independent of any further factor. However, this does not exclude the possibility that cellular factors such as TRADD or BS69 act as further stabilizers or modulators of the complex in vivo, dependent on the cellular context or the expression levels of the involved proteins. TRAF6 is critical for both canonical NF-KB and JNK activation by CTAR2 ${ }^{19,27,31}$. In contrast, TRADD is rather involved in CTAR2-induced NF-KB but not JNK signaling, whereas the situation for BS69 is vice versa $30,36,37,41$. TRADD and BS69 seem to even compete for LMP1 binding ${ }^{64,65}$, which might enable trimming of TRAF6 signaling towards canonical NF-KB, or non-canonical NF-KB and JNK activation, respectively. But how could TRAF6 and additional factors such as TRADD and BS69 interact with the same binding sequence at CTAR2 at the same time? TRADD, for instance, requires $Y_{384}$ as critical residue for its interaction with LMP1 ${ }^{36}$. LMP1 oligomerizes to form active signaling complexes ${ }^{13}$. TRAF6 itself can trimerize through its TRAF domains and further dimerize through its N-terminal RING and Zn finger domains, both together resulting in higher-order oligomerization of TRAF6 ${ }^{45,66}$. It is conceivable that LMP1 and TRAF6 form large multimeric network-like complexes at the membrane, in which not all LMP1 molecules must be occupied by TRAF6. This would allow the entry of other factors, which directly interact with $\mathrm{P}_{379}$ VQLSY. In such higher-order LMP1-TRAF6 patches, TRAF6 and BS69 (or TRADD) could be recruited to different LMP1 molecules, but still interact with each other to modulate CTAR2 signaling.

We clearly demonstrate that TRAF6 binds to CTAR2, but is unable to directly interact with CTAR1. However, it has been reported previously that TRAF6 has a role in CTAR1 signaling $19,21,26$. In mouse B 
cells, TRAF6 co-precipitates with an inducible mCD40-LMP1 fusion protein, an interaction, which is dependent on CTAR1 in these cells ${ }^{21}$. The molecular link of TRAF6 to CTAR1 might relate to the ability of TRAF6 to form heterodimers between its own RING domain and the RING domains of TRAF2, TRAF3 and TRAF5 ${ }^{67}$. Thereby, these TRAF molecules might act as bridging factors for TRAF6 interaction with CTAR1. Moreover, CTAR1 and CTAR2 co-operate in LMP1 signaling ${ }^{68}$. As shown in the present study and by others before, TRAF2, TRAF3 and TRAF 5 directly bind to CTAR $1^{12}$. Heterodimer formation between these TRAF molecules bound to CTAR1 and TRAF6 bound to CTAR2 would allow functional interaction of both CTAR domains. This hypothesis is supported by the observation that in mouse B cells both CTARs only achieve robust signaling levels in the presence of TRAF3, and that TRAF3 deficiency completely abrogates the cooperation between CTAR1 and CTAR2 ${ }^{69}$.

LMP1 expression is critically involved in pathogenesis of most EBV-associated malignant diseases such as PTLD, HL, or NPC ${ }^{1}$. There is an urgent medical need for anti-EBV drugs and counteracting LMP1 activity might constitute one promising approach to effectively manage EBV-induced uncontrolled tumor cell proliferation. Pharmacological inhibition of LMP1-induced NF-KB and JNK signaling has already been shown to result in cell death and reduced tumor growth, respectively $23,34,70,71$. However, continuous systemic NF-KB and JNK inhibition might entail adverse side effects that restrict treatment. Instead, the interface between the viral oncoprotein LMP1 and its critical cellular interaction partner offers a more specific target for pharmacological intervention. Here, we have identified and validated the direct LMP1TRAF6 complex as a novel target for inhibitory molecules, in our case peptides. Moreover, the deletion of TRAF6 in LMP1-driven mouse B cell lymphomas was as effective as deletion of LMP1 itself in killing the tumor cells. The next step towards an effective anti-LMP1 drug could be the screening for specific small molecule inhibitors of LMP1-TRAF6 interaction. Protein-protein interactions are nowadays regarded as well-druggable targets for small molecules ${ }^{72}$. The unique structure of this viral/cellular complex should facilitate the identification of LMP1-specific inhibitors, which show fewer unwanted side effects on cellular TRAF6 interactions. AlphaScreen-based LMP1-TRAF6 protein-protein interaction assay technology developed in the present work will allow high-throughput screening for such inhibitory small molecules in the future.

\section{Methods}

\section{Plasmids}

The vectors pGEX2T-LMP1 $1_{181-386}$, pGEX2T-stop, pET17b-His-TRAF2 ${ }_{311-501}$, pET17b-His-TRAF6 $6_{310-522} 32$ pET17b-His-TRAF3 $375-568{ }^{73}{ }^{7}$, pGag-pol-IRES-bs ${ }^{r}$, pEnv-IRES-puror ${ }^{74}$, pRK5-Flag-TRAF6 ${ }^{32}$, pSV-NGFRLMP1 ${ }^{13}$, pCMV-HA-LMP1 $\left(\mathrm{A}_{204} \mathrm{XAXA}\right)$ and PCMV-HA-LMP1 $\left(\mathrm{A}_{204} \times \mathrm{AXA} / \Delta 371-386\right){ }^{30}$, as well as the retroviral vectors pSF91-IRES-GFP-WPRE ${ }^{75}$ and pSF91-NGFR-LMP1-IRES-GFP-WPRE ${ }^{34}$ have been described. For recombinant human TRAF1, TRAF4 and TRAF5 expression, pET17b-His-TRAF1 226-416, pET17b-His-TRAF4 282-470, and pET17b-His-TRAF5 ${ }_{363-557}$ were cloned by PCR from cDNAs into the 
pET17b vector (Novagen). Single amino acid exchanges $R_{392} A, K_{469} A, F_{471} A, Y_{473} A$ within pET17b-HisTRAF6 $6_{310-522}$ and pRK5-Flag-TRAF6 were carried out by PCR-based site-directed mutagenesis. The TRAF6 expression vector pET-hSu-TRAF6 ${ }_{346-504}$ was cloned by PCR based on His-TRAF6 $310-522$. The GST-LMP1 mutants $A_{204} X A x A, Y_{384} G, \Delta 371-386, A_{379} x A x x A, G_{378} A, P_{379} A, V_{380} A, Q_{381} A, Q_{381} E, L_{382} A$, $\mathrm{S}_{383} \mathrm{~A}, \mathrm{Y}_{384} \mathrm{~A}, \mathrm{Y}_{384} \mathrm{~F}$, and $\mathrm{Y}_{385} \mathrm{~A}$ were generated on the basis of pGEX2T-LMP1 ${ }_{181-386}$ by PCR. pGEX-2T$\mathrm{CD}_{40} \mathrm{2}_{216-277}$, and pGEX-2T-CD 40 $216-277\left(\mathrm{~A}_{233} \mathrm{XAXXA}\right)$ were cloned by PCR based on human CD40 CDNA. Flag-TRAF6 and the mutants $R_{392} A, F_{471} A$ and $Y_{473} A$ were subcloned into the vector $p S F 91-I R E S-C F P-$ WPRE. Detailed cloning strategies, primer sequences and sequencing results will be made available upon request.

\section{Cell culture, retroviral transduction, and NGFR-LMP1 activation}

Wildtype MEFs and derivatives thereof, TRAF6 -/-MEFs ${ }^{76}$, and HeLa cells (obtained from the German Collection of Microorganisms and Cell Cultures, GCMC) were kept in Dulbecco's modified Eagle's medium (DMEM, Thermo Fischer, \#41966-029). The cell lines HEK293 (obtained from GCMC), HA-LCL3 ${ }^{30}$, LCL721 $77, \mathrm{BL} 41^{78}$ and the mouse lymphomas LMP1-CL 37 and 40 were kept in Roswell Park Memorial Institute medium (RPMI 1640, Thermo Fisher, \#21875-034). If not indicated otherwise, DMEM and RMPI were supplemented with $10 \%$ of fetal bovine serum (Sigma, \#F7524), 1 mM L-Glutamine (Thermo Fisher, \#25030-024) and antibiotics (50 U/mL Penicilline and $50 \mu \mathrm{g} / \mathrm{mL}$ Streptomycine). All cells were kept at $37^{\circ} \mathrm{C}$ in the presence of $5 \% \mathrm{CO}_{2}$. Retroviral transduction of MEFs with NGFR-LMP1 and TRAF6 was carried out as described using the vectors pSF91-NGFR-LMP1-IRES-GFP-WPRE and pSF91-Flag-TRAF6IRES-CFP-WPRE expressing TRAF6 wildtype or the indicated TRAF6 mutants ${ }^{34}$. For NGFR-LMP1 crosslinking, $1 \mu \mathrm{g} / \mathrm{mL}$ of a-NGFR primary antibody (ATCC, clone HB8737) was added for $1 \mathrm{~h}$ to the cells. Signaling was activated by further addition of $10 \mu \mathrm{g} / \mathrm{mL}$ of a-mouse $\mathrm{lgG} / \mathrm{lgM}$ secondary antibody (Dianova, \#115-005-068) for given time points.

\section{CRISPR/CAS9}

The mouse LMP1 B cell tumors LMP1-CL 37 and 40 were derived from two B cell tumors arising in $R a g 2^{K O} ; \mathrm{CY}^{K O}$ mice inoculated with primary tumor cells from $\mathrm{Rag}{ }^{\mathrm{KO}} ; \mathrm{CY}^{\mathrm{KO}}$ mice reconstituted with fetal

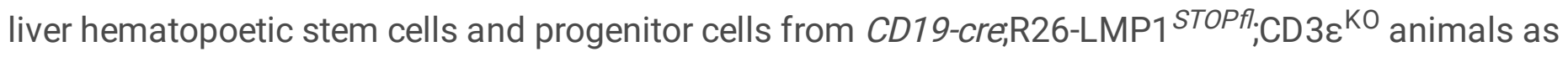
described ${ }^{9}$. In these cells, a Venus expression cassette was targeted into the Rosa26 locus by CRISPR/CAS9 as described ${ }^{79}$. Venus-LMP1 B cells were electroporated (Nucleofector, Lonza, human B cell program) with $1 \mu \mathrm{g}$ of each of two pX330-mcherry-CAS9 vectors ${ }^{80}$ encoding varying guide RNAs. In each approach, the first guide RNA (gRNA) targeted Venus while the second gRNA targeted either a nontargeting control sequence not present in the genome, or the gene of interest (GOI). The following gRNA sequences were used: non-targeting (NT) ACTCCAGTCTTTCTAGAAGA, ICAM1

GTTTGAGCTGAGCGAGATCG, LMP1 \#1 TTAATCTGGATGTATTACCA, LMP1 \#2

Page $14 / 39$ 
CCAAAACAGTAGCGCCAAG, LMP1 \#3 AATCATCGGTAGCTTGTTG, TRAF6 \#1

TGTGGAGTTTGACCCACCTC, TRAF6 \#2 TCTGGACGACATCCCCGGGA, TRAF6 \#3

CATCGCACGGACGCAAAGCA. The electroporation efficiency, measured as frequency of mCherry positive cells at day two after electroporation, was determined by flow cytometry with a Becton Dickinson Fortessa flow cytometer. At day seven, loss of Venus was measured by flow cytometry as surrogate marker for the number of surviving targeted cells. In the case of a lethal co-expressed GOI gRNA, Venusnegative cells will not survive and their relative numbers are reduced. The given selection score is defined as the frequency of Venus-negative cells on day seven over the frequency of mCherry-positive cells on day two, normalized to the ratio observed with the non-targeting control gRNA. FACS data were analysed by FlowJo software. Animal housing and experiments to generate LMP1 lymphomas were approved by the Landesamt für Gesundheit und Soziales Berlin (G0049/15, G0374/13, and G0135/11).

\section{Purification of His-tagged proteins}

For protein expression, $400 \mathrm{~mL}$ of bacterial cultures (BL21 Codon Plus RIPL, Agilent Technologies, \#230280) in lysogeny broth (LB)-medium (supplemented with $50 \mu \mathrm{g} / \mathrm{mL} \mathrm{Amp}$ and $34 \mu \mathrm{g} / \mathrm{mL}$ Cam) were induced with $0.1 \mathrm{mM} I P T G$ at $\mathrm{OD}_{600}$ of $0.8-1.0$. Protein expression was carried out overnight at $20^{\circ} \mathrm{C}$ while shaking at $200 \mathrm{rpm}$. Cells were pelleted (3500 x g, 20 minutes, $\left.4^{\circ} \mathrm{C}\right)$, resuspended in sodium phosphate buffer (50 mM sodium phosphate, $300 \mathrm{mM} \mathrm{NaCl}, 10 \mathrm{mM}$ imidazole, pH 8.0) supplemented with a protease inhibitor cocktail (cOmplete, Roche; following manufacturer's instructions) and lysed by adding $1 \mathrm{mg} / \mathrm{mL}$ (final concentration, f. c.) lysozyme (Merck \#9001-63-2) followed by sonification on ice (three times 10 seconds at 30 - 50\% amplitude, on ice). Lysates were incubated on ice for 20 minutes and cleared from insoluble debris by centrifugation (10000 x g, 30 minutes, $4^{\circ} \mathrm{C}$ ), loaded onto $\mathrm{Ni}^{2+}-\mathrm{NTA}^{-}$ agarose beads (Quiagen, \#30210), and incubated for $1 \mathrm{~h}$ at $4^{\circ} \mathrm{C}$. Beads were washed stepwise with 20 $\mathrm{mM}, 50 \mathrm{mM}$ and $100 \mathrm{mM}$ imidazole in sodium phosphate buffer. His-TRAF proteins were eluted with 500 $\mathrm{mM}$ imidazole in sodium phosphate buffer. For buffer exchange, proteins were loaded onto Dextra-Sec Pro-10 columns (AppliChem) and eluted in PBS according to manufacturer's instructions. Samples were supplemented with $10 \%$ glycerol (f. c.) and stored at $-20^{\circ} \mathrm{C}$.

\section{Purification of GST-tagged proteins}

For protein expression $400 \mathrm{~mL}$ bacterial cultures (DH5a or BL21 Codon Plus RIPL), transformed with the corresponding expression plasmids where grown in LB-medium supplemented with appropriate antibiotics and induced with $0.1 \mathrm{mM} I P T G$ at $\mathrm{OD}_{600}=0.8-1.0$. Protein expression was carried out overnight at $20^{\circ} \mathrm{C}$. Cells were pelleted $\left(3500 \mathrm{x} \mathrm{g}, 20\right.$ minutes, $\left.4^{\circ} \mathrm{C}\right)$, resuspended in $\mathrm{PBS}(\mathrm{pH} 7,4)$ supplemented with $0.1 \%$ Tween-20 and protease inhibitor cocktail (cOmplete, Roche), and lysed by adding of $1 \mathrm{mg} / \mathrm{mL}$ (f. c.) lysozyme followed by sonification. Lysates were incubated on ice for 20 minutes, cleared from insoluble debris by centrifugation $\left(10000 \mathrm{xg}, 30\right.$ minutes, $\left.4^{\circ} \mathrm{C}\right)$, loaded onto Glutathione Sepharose 4B beads (GE Healthcare) and incubated for $2-4 \mathrm{~h}$ at $4^{\circ} \mathrm{C}$. Beads were washed three times with PBS and bound proteins were eluted with $500 \mathrm{mM}$ reduced Glutathione in PBS. For buffer exchange, all proteins were loaded onto Dextra-Sec Pro-10 columns (AppliChem) and eluted in PBS 
according to manufactures instructions. Samples were supplemented with $10 \%$ glycerol and stored at $-20^{\circ} \mathrm{C}$.

\section{AlphaScreen PPI assays}

AlphaScreen experiments were performed in 96- or 384-well plates (Perkin Elmer, OptiPlate). In both assay formats, His-TRAF and GST-LMP1 proteins were incubated together in $40 \mu \mathrm{L}$ of PBS (protein concentrations were calculated to the final reaction volume of $60 \mu \mathrm{L}$ ) supplemented with $0.5 \% \mathrm{BSA}$ (Sigma, \#A7030) and 0.1\% Tween-20 (AppliChem, \#A4974), for $1 \mathrm{~h}$ at room temperature (RT). If not indicated otherwise, standard protein concentrations were $300 \mathrm{nM}$ for His-TRAF proteins and $100 \mathrm{nM}$ for GST-LMP1 proteins. Ni-NTA-acceptor (Perkin Elmer, \#6760619C) and GST-acceptor (Perkin Elmer, \# 6765300 ) beads were added each to a final concentration of $1-3 \mu \mathrm{g} / \mathrm{mL}$ in a final reaction volume of 60 $\mu \mathrm{L}$ and incubated for $1 \mathrm{~h}$ at RT in the dark. AlphaScreen PPI signals were measured in a CLARIOstar reader (BMG Labtech $\mathrm{GmbH}$ ).

\section{Pulldown experiments}

$10 \mu \mathrm{L}$ of a $50 \%$ slurry of Glutathione Sepharose 4B beads (GE Healthcare) were loaded with $80 \mu \mathrm{g}$ of purified GST-LMP1 or $40 \mu \mathrm{g}$ of GST, as indicated, for $2-4 \mathrm{~h}$ at $4^{\circ} \mathrm{C}$ in $500 \mu \mathrm{L}$ PBS in an overhead shaker. Beads were pelleted at $500 \times \mathrm{g}$ for 5 minutes at $4^{\circ} \mathrm{C}$, and washed twice with PBS. Beads loaded with GSTLMP1 or GST control were then further incubated with $1,5 \mu \mathrm{g}$ of His-TRAF proteins in $500 \mu \mathrm{L}$ PBS supplemented with $0.1 \% \mathrm{BSA}$ and $0.1 \%$ Tween-20 for $1 \mathrm{~h}$ at $4^{\circ} \mathrm{C}$. Beads were pelleted, washed three times with PBS containing $0.1 \%$ Tween and resuspended in $75 \mu \mathrm{L}$ of Laemmli SDS sample buffer. Samples were loaded onto $15 \%$ SDS-PAA gels and proteins were separated by SDS-PAGE. GST-LMP1 proteins were visualized by incubation of the SDS-PAA gels in $20 \%$ acetic acid containing $1 \%$ Coomassie Blue G-250 (Serva). Free dye was removed by repeated incubation in $10 \%$ acetic acid. Amounts of His-TRAF proteins were analysed by immunoblotting using a-6*His-tag antibody.

\section{Immunoblotting}

Immunoblotting was essentially performed as described ${ }^{34}$. Proteins were detected on nitrocellulose membranes (Bio-Rad, \#1620115) using the following primary antibodies: a-6*His-tag (clone 4A4 or 2F12, source: antibody facility of the Helmholtz Center Munich), a-TRAF6 (H-274, \#sc-7221, Santa Cruz Biotech.), a-HA-tag (12CA5, \#11583816001, Sigma-Aldrich), a-lkBa (C-21, \#sc-371, Santa Cruz Biotech.) and a-Tubulin (B-5-1-2, \#sc-23948, Santa Cruz Biotech.). Horseradish peroxidase-coupled antibodies were used as secondary antibodies (Cell Signaling Technology \#7074 or \#7076, respevtively). ECL signals were captured on X-ray films (Agfa Healthcare) and quantified by densitometry using the ImageJ software.

\section{Immunoprecipitations}

HEK293 cells were transfected with $1 \mu \mathrm{g}$ of pRK5-Flag TRAF6 plasmids, $1 \mu \mathrm{g}$ of pCMV-HA-LMP1 and $6 \mu \mathrm{g}$ of pRK5 per $10 \mathrm{~cm}$ cell culture dish using PolyFect Transfection Reagent (Qiagen, \#301107) in RPMI without supplements. Cells were incubated with the plasmid transfection mix for $4 \mathrm{~h}$ before medium was 
changed to RPMI full medium. After 24, the cells were lysed in NP40-lysis buffer ( $50 \mathrm{mM}$ Hepes $\mathrm{pH} 7.5$, $150 \mathrm{mM} \mathrm{NaCl}, 5 \mathrm{mM}$ EDTA, $0.5 \mathrm{mM}$ sodium orthovanadate, $0.5 \mathrm{mM}$ PMSF, $0.5 \mathrm{mM}$ sodium molybdate, and cOmplete protease inhibitor cocktail). Lysates were cleared by centrifugation at $15000 \mathrm{xg}$ for $10 \mathrm{~min}$ at $4^{\circ} \mathrm{C}$ and protein concentration was adjusted to $1 \mathrm{mg} / \mathrm{mL}$. For immunoprecipitation $4 \mathrm{~mL}$ of lysates were incubated with the a-Flag antibody 6F7 (Sigma-Aldrich; covalently coupled to protein-G-Sepharose) for $1 \mathrm{~h}$ at $4^{\circ} \mathrm{C}$. Beads were pelleted at $15000 \mathrm{xg}$ for 30 seconds at $4^{\circ} \mathrm{C}$, washed twice with NP40-lysis buffer, and analysed by immunoblotting.

\section{NF-kB reporter assay}

$6 \times 10^{4}$ TRAF6 $\%$ - cells were seeded per well of a 6-well plate in DMEM full medium the day before transfection. Cells were transfected with $2 \mu \mathrm{g}$ of the indicated pCMV-HA-LMP1 plasmids together with 0.9 $\mu \mathrm{g}$ of pRK5-Flag-TRAF6 plasmids or empty vector, $0.05 \mu \mathrm{g}$ of NF-KB luciferase reporter 3xKB-Luc and 0.2 $\mu \mathrm{g}$ of pPGK-Renilla housekeeping control reporter using the PolyFect transfection reagent (Qiagen) as described ${ }^{32}$. After $4 \mathrm{~h}$ the transfection mix was removed and cells were kept overnight in DMEM full medium. NF-KB reporter and Renilla control activities were measured with the Dual-Luciferase reporter assay kit (Promega, \#E1910) following the manufacturer's instructions. Samples of each lysate were analysed for LMP1 and TRAF6 expression by immunoblotting.

\section{Peptide arrays}

Arrays were synthesized on a Multipep Synthesizer (Intavis Bioanalytical Instruments) on derivatized cellulose (amino-Peg500 UC540, acid-hardened, loading $400 \mathrm{nmol} / \mathrm{cm}^{2}$, Intavis). After peptides were spotassembled and deprotected, membranes were washed extensively with dichlormethane, $\mathrm{N}$ methylpyrolidone, and ethanol and stored at $-20^{\circ} \mathrm{C}$ until use. Prior to use, filters were rinsed for $10 \mathrm{sec}$ in ethanol and washed three times for ten min each at $50 \mathrm{rpm}$ in PBST (PBS, $0.1 \%$ Tween-20) under gentle rocking. Filters were blocked by incubation in PBST supplemented with $5 \%(\mathrm{w} / \mathrm{v})$ non-fat dry milk powder for $2 \mathrm{~h}$ at RT and three washing steps in PBST for 20 min. Subsequently, unspecific antibody binding sites were blocked by incubation of the filters at $4^{\circ} \mathrm{C}$ overnight with either TRAF6 (goat a-TRAF6 C-20 \#sc6223, Santa Cruz Biotech.) or TRAF2 primary antibody (rabbit a-TRAF2 C-20, \#sc-876, Santa Cruz Biotech.), diluted at 1:1000 in PBS supplemented with $5 \%(\mathrm{w} / \mathrm{v})$ non-fat dry milk powder. Following three washing steps with PBS, the filters were incubated with horseradish peroxidase-conjugated a-goat lgG (Dianova, \#305-035-003) or a-rabbit IgG (Cell Signaling Technology, \#7074S) secondary antibody, diluted 1:5000 in PBS supplemented with $5 \%(\mathrm{w} / \mathrm{v})$ non-fat dry milk powder. Filters were developed with ECL and no unspecific antibody binding was detected. To detect TRAF6 or TRAF2 binding to the immobilized peptides, filters were washed with PBST and subsequently incubated with $10 \mu \mathrm{g} / \mathrm{mL}$ of recombinant purified His-TRAF6 or His-TRAF2 protein in PBST supplemented with $5 \%(\mathrm{w} / \mathrm{v})$ non-fat dry milk powder for $4 \mathrm{~h}$ at RT. After washing of filters in PBST, TRAF protein binding was analysed by incubation of the filters with TRAF6 or TRAF2 primary and the respective secondary antibodies. ECL signals were captured on X-ray films (Agfa Healthcare).

\section{Structural Modeling}


A 3D model of the LMP1 peptide $\mathrm{H}_{377}$ GPVQLSY interacting with TRAF6 was derived with Molecular Operating Environment (MOE) software 2013.08 of Chemical Computing Group ULC (1010 Sherbrokke St. West, Suite \#910, Montreal, QC, Canada), from a structure of a MAVS-TRAF6 complex (PDB 4Z8M). The Amber10:EHT force field was used for all calculations. 4Z8M was prepared with the Structure Preparation with default settings. This procedure included the correction of structural issues, in particular those related to missing atoms in side chains and at the termini, and the computation of protonation states with Protonate3D (with default settings). Whereas no further alterations were made to the structure of TRAF6, the LMP1 peptide was derived from the MAVS structure by the mutation of individual amino acids using the Protein Builder with default settings. Next, the side chains of all of the mutated residues were minimized with the MOE Protein Builder. Images were generated with PyMol Molecular Graphics System Version 2.4.2 (Schrödinger LLC).

\section{NMR Spectroscopy}

For NMR a His-SUMO-TRAF6 fusion construct was expressed in E.coli Rosetta2 DE3 cells from pET-hSu$\mathrm{TRAF}_{346-504}$. The recombinant protein was uniformly labeled with ${ }^{15} \mathrm{~N}$ by growing expression cultures in ${ }^{15} \mathrm{~N}$-auto-induction medium ${ }^{81}$. TRAF6 protein was purified from cell lysate via IMAC using a Ni-NTA column. After elution, the protein was transferred to $100 \mathrm{mM}$ Tris- $\mathrm{HCl} \mathrm{pH} \mathrm{8.0,300} \mathrm{mM} \mathrm{NaCl,} 20 \mathrm{mM}$ imidazole, $5 \mathrm{mM} \beta$-mercaptoethanol. SUMO-hydrolase dtUD1 was added (ratio 1:50) and incubated overnight at $4^{\circ} \mathrm{C}$. After cleavage, the protein was subjected to a second Ni-NTA affinity chromatography step and then further purified via size-exclusion chromatography using a Superdex 75 10/300 GL column (Äkta system, GE Healthcare). SEC buffer was PBS (37 mM NaCl, $2.7 \mathrm{mM} \mathrm{KCl}, 10 \mathrm{mM} \mathrm{Na}{ }_{2} \mathrm{HPO}_{4}, 1.8 \mathrm{mM}$ $\mathrm{KH}_{2} \mathrm{PO}_{4} \mathrm{pH} 7.4,5 \mathrm{mM} \beta-\mathrm{ME}$ ) and has been subsequently used in the following NMR experiments. NMR spectra were recorded at $298 \mathrm{~K}$ using a Bruker Avance 600 spectrometer with QCl cryogenic probe and topspin v.3.2 software (Bruker BioSpin). Spectra were processed using NMRDraw v.8.7 of the NMRPipe software ${ }^{82}$ and analysed with the CCPN Analysis software v.2.4.1 ${ }^{83}$. NMR titrations were performed by recording ${ }^{1} \mathrm{H},{ }^{15} \mathrm{~N}$ HSQC experiments. For titrations of TRAF6, samples of $90 \mu \mathrm{M}{ }^{15} \mathrm{~N}$-labeled TRAF6 in PBS pH 7.4, $10 \% \mathrm{D}_{2} \mathrm{O}, 5 \mathrm{mM} \beta$-ME were used. Samples contained either no ligand (reference), or five-fold excess of unlabeled LMP1 peptides (PSL) as indicated. Shifts were highlighted in the TRAF6-LMP1 model using PyMol software (Schrödinger LLC). TRAF6 residues were annotated on the basis of the previously published partial backbone chemical shift assignment of TRAF6 ${ }^{59}$.

\section{Confocal Immunofluorescence}

HeLa cells were seeded onto cover glasses (Thermo Scientific, Menzel) in 24-well plates one day prior to transfection. Cells were transfected at $50-60 \%$ confluency with $50 \mathrm{ng}$ of pCMV-HA-LMP1 plasmids and $100 \mathrm{ng}$ of pRK5-Flag-TRAF6 plasmids, adjusted to a total of $500 \mathrm{ng}$ DNA per sample with pRK5 empty vector, using Lipofectamine 2000 (Thermo Fisher Scientific) according to the manufacturer's instructions. At $24 \mathrm{~h}$ post-transfection, cells were washed once with PBS and fixed with $4 \%$ paraformaldehyde (SigmaAldrich) for 20 min at RT, followed by permeabilisation with $0.3 \%(v / v)$ Triton X-100 and blocking with 5\% $(\mathrm{v} / \mathrm{v})$ fetal bovine serum in PBS for $1 \mathrm{~h}$ at RT. For immunostaining, the cells were incubated overnight with 
the primary antibodies a-HA (1:1000, clone 16B12, BioLegend) and a-DYKDDDDK (1:1000, clone L5, BioLegend) at $4^{\circ} \mathrm{C}$. The secondary antibodies goat a-mouse Alexa 488 (1:500, cross-adsorbed, Invitrogen \#A-11029) and goat a-rat Alexa 555 (1:500, cross-adsorbed, Invitrogen \#A-21434) were added for $1.5 \mathrm{~h}$ at RT. Microscope slides were sealed with cover glasses using Mowiol mounting medium (Sigma-Aldrich). Nuclei were stained with Hoechst 33258 (Sigma-Aldrich). All samples were imaged using a Leica TCS SP5 confocal microscope with $405 \mathrm{~nm}, 488 \mathrm{~nm}, 543 \mathrm{~nm}$ or $633 \mathrm{~nm}$ laser lines, scanning each channel separately under image capture conditions that eliminated channel overlap. Per single experiment, 10 transfected cells positive for both constructs were randomly captured as single cell images for quantification. The resulting images were then analysed using the Leica TCS SP5 co-localization analyses application (LAS AF Version 2.7.3.9723). Analysis was performed with default parameters.

\section{MTT cell viability assay}

At day zero, $10^{4}$ cells were seeded in in 96-well plates in the presence of $100 \mu \mathrm{M}$ TRAF6 inhibitor peptide (NBP2-26506, Novus Biologicals) or control peptide in $100 \mu \mathrm{L}$ RPMI full medium. Cells were incubated at $37^{\circ} \mathrm{C}$ and $5 \% \mathrm{CO}_{2}$. At day three, $10 \mu \mathrm{L}$ of $0.5 \mathrm{mg} / \mathrm{mL}$ MTT (3-(4,5-Dimethylthiazol-2-yl)-2,5-

Diphenyltetrazolium Bromide) was added. After $4 \mathrm{~h}$, MTT turnover was analysed by adding $200 \mu \mathrm{L}$ of $\mathrm{HCl}$ :Isopropanol (ratio 1:24). The blue reaction product was measured at $550 \mathrm{~nm}$ with a reference filter at $690 \mathrm{~nm}$.

\section{Statistics}

All statistical analysis was performed with Prism 6 software (GraphPad Software Inc.). Two-way ANOVA was performed on experiments with two factors of variance (Figure 1E and $3 \mathrm{~A}$ ). Ordinary one-way ANOVA with multiple comparisons was performed on experiments with one factor of variance (Figure 2A, 2C, 3C $6 B, 7 C$ and Supplementary Figure $2 A$ ). For $K_{D}$ determination the data from each experiment was cleaned for hook effect (signal depletion by oversaturation of the beads) and analysed using the equation "one site - specific binding with hill slope" (Figure $1 \mathrm{~F}$ and $1 \mathrm{G}$ ). $\mathrm{IC}_{50}$ was determined using the "log(inhibitor) vs. response - variable slope (four parameters)" equation (Figure 7B and 7D). Paired t-test was used for matched samples (Figure 7B and 7D) and unpaired t-test for not unpaired samples (Figure 7E).

\section{Declarations}

\section{ACKNOWLEDGMENTS}

We thank Ichio Shimada of the University of Tokyo for generously sharing NMR assignment data of TRAF6. This work was supported by grant Ki 825/1-3 by the German Research Foundation (DFG), and grants TTU 07.802, TTU 07.809, and TTU 07.825 by the German Research Center for Infection Research (DZIF), and the Life Science Foundation to A.K.

\section{AUTHOR CONTRIBUTIONS}

A.K. designed and supervised the project, analysed and interpreted data and wrote the manuscript, F.G. conducted experiments, analysed and interpreted data and wrote the manuscript, M.O., T.S., D.W. and 
K.R.S, conducted experiments, analysed and interpreted data, H.K. and A.G. conducted experiments, S.M.F. contributed essential material and protocols, B.B. and G.P. analysed and interpreted data, J.K. conducted in silico modeling, analysed and interpreted data. All authors reviewed the manuscript.

\section{COMPETING INTERESTS}

The authors declare no competing interests.

\section{References}

1. Young, L. S., Rickinson, A. B. Epstein-Barr virus: 40 years on. Nat. Rev. Cancer 4, 757-768 (2004).

2. Munz, C. Latency and lytic replication in Epstein-Barr virus-associated oncogenesis. Nat. Rev. Microbiol. 17, 691-700 (2019).

3. Khan, G., Hashim, M. J. Global burden of deaths from Epstein-Barr virus attributable malignancies 1990-2010. Infect. Agent. Cancer 9, 38 (2014).

4. Kaye, K. M., Izumi, K. M., Kieff, E. Epstein-Barr virus latent membrane protein 1 is essential for Blymphocyte growth transformation. Proc. Natl. Acad. Sci. U.S.A. 90, 9150-9154 (1993).

5. Wang, D., Liebowitz, D., Kieff, E. An EBV membrane protein expressed in immortalized lymphocytes transforms established rodent cells. Cell 43, 831-840 (1985).

6. Baichwal, V. R., Sugden, B. Transformation of Balb $3 T 3$ cells by the BNLF-1 gene of Epstein-Barr virus. Oncogene 2, 461-467 (1988).

7. Kilger, E., Kieser, A., Baumann, M., Hammerschmidt, W. Epstein-Barr virus-mediated B-cell proliferation is dependent upon latent membrane protein 1, which simulates an activated CD40 receptor. EMBO J. 17, 1700-1709 (1998).

8. Dirmeier, U., Neuhierl, B., Kilger, E., Reisbach, G., Sandberg, M. L., Hammerschmidt, W. Latent membrane protein 1 is critical for efficient growth transformation of human B cells by Epstein-Barr virus. Cancer Res. 63, 2982-2989 (2003).

9. Zhang, B., et al. Immune surveillance and therapy of lymphomas driven by Epstein-Barr virus protein LMP1 in a mouse model. Cell 148, 739-751 (2012).

10. Minamitani, T., et al. Mouse model of Epstein-Barr virus LMP1- and LMP2A-driven germinal center Bcell lymphoproliferative disease. Proc. Natl. Acad. Sci. U.S.A. 114, 4751-4756 (2017).

11. Chen, Y. P., et al. Effect of latent membrane protein 1 expression on overall survival in Epstein-Barr virus-associated cancers: a literature-based meta-analysis. Oncotarget 6, 29311-29323 (2015).

12. Kieser, A., Sterz, K. R. The Latent Membrane Protein 1 (LMP1). Curr. Top. Microbiol. Immunol. 391, 119-149 (2015).

13. Gires, O., et al. Latent membrane protein 1 of Epstein-Barr virus mimics a constitutively active receptor molecule. EMBO J. 16, 6131-6140 (1997).

14. Mosialos, G., Birkenbach, M., Yalamanchili, R., VanArsdale, T., Ware, C., Kieff, E. The Epstein-Barr virus transforming protein LMP1 engages signaling proteins for the tumor necrosis factor receptor family. 
Cell 80, 389-399 (1995).

15. Devergne, O., et al. Association of TRAF1, TRAF2, and TRAF3 with an Epstein-Barr virus LMP1 domain important for B-lymphocyte transformation: role in NF-kappaB activation. Mol. Cell. Biol. 16, 7098-7108 (1996).

16. Sandberg, M., Hammerschmidt, W., Sugden, B. Characterization of LMP-1's association with TRAF1, TRAF2, and TRAF3. J. Virol. 71, 4649-4656 (1997).

17. Brodeur, S. R., Cheng, G., Baltimore, D., Thorley-Lawson, D. A. Localization of the major NF-kappaBactivating site and the sole TRAF3 binding site of LMP-1 defines two distinct signaling motifs. J. Biol. Chem. 272, 19777-19784 (1997).

18. Eliopoulos, A. G., Gallagher, N. J., Blake, S. M., Dawson, C. W., Young, L. S. Activation of the p38 mitogen-activated protein kinase pathway by Epstein-Barr virus-encoded latent membrane protein 1 coregulates interleukin-6 and interleukin-8 production. J. Biol. Chem. 274, 16085-16096 (1999).

19. Schultheiss, U., et al. TRAF6 is a critical mediator of signal transduction by the viral oncogene latent membrane protein 1. EMBO J. 20, 5678-5691 (2001).

20. Dawson, C. W., Laverick, L., Morris, M. A., Tramoutanis, G., Young, L. S. Epstein-Barr virus-encoded LMP1 regulates epithelial cell motility and invasion via the ERK-MAPK pathway. J. Virol. 82, 36543664 (2008).

21. Arcipowski, K. M., Stunz, L. L., Graham, J. P., Kraus, Z. J., Vanden Bush, T. J., Bishop, G. A. Molecular mechanisms of TNFR-associated factor 6 (TRAF6) utilization by the oncogenic viral mimic of CD40, latent membrane protein 1 (LMP1). J. Biol. Chem. 286, 9948-9955 (2011).

22. Eliopoulos, A. G., Waites, E. R., Blake, S. M., Davies, C., Murray, P., Young, L. S. TRAF1 is a critical regulator of JNK signaling by the TRAF-binding domain of the Epstein-Barr virus-encoded latent infection membrane protein 1 but not CD40. J. Virol. 77, 1316-1328 (2003).

23. Kutz, H., Reisbach, G., Schultheiss, U., Kieser, A. The c-Jun N-terminal kinase pathway is critical for cell transformation by the latent membrane protein 1 of Epstein-Barr virus. Virology 371, 246-256 (2008).

24. Greenfeld, H., et al. TRAF1 Coordinates Polyubiquitin Signaling to Enhance Epstein-Barr Virus LMP1Mediated Growth and Survival Pathway Activation. PLoS Pathog. 11, e1004890 (2015).

25. Wang, L., et al. The Linear Ubiquitin Assembly Complex Modulates Latent Membrane Protein 1 Activation of NF-kappaB and Interferon Regulatory Factor 7. J. Virol. 91, e01138-16 (2017).

26. Wang, L., Ning, S. New Look of EBV LMP1 Signaling Landscape. Cancers (Basel) 13, 5451 (2021).

27. Luftig, M., et al. Epstein-Barr virus latent membrane protein 1 activation of NF-kappaB through IRAK1 and TRAF6. Proc. Natl. Acad. Sci. U.S.A. 100, 15595-15600 (2003).

28. Wu, L., Nakano, H., Wu, Z. The C-terminal activating region 2 of the Epstein-Barr virus-encoded latent membrane protein 1 activates NF-kappaB through TRAF6 and TAK1. J. Biol. Chem. 281, 2162-2169 (2006). 
29. Ning, S., Campos, A. D., Darnay, B. G., Bentz, G. L., Pagano, J. S. TRAF6 and the three C-terminal lysine sites on IRF7 are required for its ubiquitination-mediated activation by the tumor necrosis factor receptor family member latent membrane protein 1. Mol. Cell. Biol. 28, 6536-6546 (2008).

30. Schneider, F., et al. The viral oncoprotein LMP1 exploits TRADD for signaling by masking its apoptotic activity. PLoS Biol. 6, e8 (2008).

31. Wan, J., et al. Elucidation of the c-Jun N-terminal kinase pathway mediated by Estein-Barr virusencoded latent membrane protein 1. Mol. Cell. Biol. 24, 192-199 (2004).

32. Shkoda, A., et al. The germinal center kinase TNIK is required for canonical NF-kappaB and JNK signaling in B-cells by the EBV oncoprotein LMP1 and the CD40 receptor. PLoS Biol. 10, e1001376 (2012).

33. Wang, L., et al. LIMD1 is induced by and required for LMP1 signaling, and protects EBV-transformed cells from DNA damage-induced cell death. Oncotarget 9, 6282-6297 (2018).

34. Voigt, S., et al. A central role of IKK2 and TPL2 in JNK activation and viral B-cell transformation. Nat. Commun. 11, 685 (2020).

35. Ishida, T., et al. Identification of TRAF6, a novel tumor necrosis factor receptor-associated factor protein that mediates signaling from an amino-terminal domain of the CD40 cytoplasmic region. J. Biol. Chem. 271, 28745-28748 (1996).

36. Izumi, K. M., Kieff, E. D. The Epstein-Barr virus oncogene product latent membrane protein 1 engages the tumor necrosis factor receptor-associated death domain protein to mediate $B$ lymphocyte growth transformation and activate NF-kappaB. Proc. Natl. Acad. Sci. U.S.A. 94, 12592-12597 (1997).

37. Kieser, A., Kaiser, C., Hammerschmidt, W. LMP1 signal transduction differs substantially from TNF receptor 1 signaling in the molecular functions of TRADD and TRAF2. EMBO J. 18, 2511-2521 (1999).

38. Kieser, A. Pursuing different 'TRADDes': TRADD signaling induced by TNF-receptor 1 and the EpsteinBarr virus oncoprotein LMP1. Biol. Chem. 389, 1261-1271 (2008).

39. Floettmann, J. E., Rowe, M. Epstein-Barr virus latent membrane protein-1 (LMP1) C-terminus activation region 2 (CTAR2) maps to the far C-terminus and requires oligomerisation for NF-kappaB activation. Oncogene 15, 1851-1858 (1997).

40. Franken, M., Devergne, O., Rosenzweig, M., Annis, B., Kieff, E., Wang, F. Comparative analysis identifies conserved tumor necrosis factor receptor-associated factor 3 binding sites in the human and simian Epstein-Barr virus oncogene LMP1. J. Virol. 70, 7819-7826 (1996).

41. Wan, J., et al. BS69, a Specific Adaptor in the Latent Membrane Protein 1-Mediated c-Jun N-Terminal Kinase Pathway. Mol. Cell. Biol. 26, 448-456 (2006).

42. Arch, R. H., Gedrich, R. W., Thompson, C. B. Tumor necrosis factor receptor-associated factors (TRAFs)--a family of adapter proteins that regulates life and death. Genes Dev. 12, 2821-2830 (1998).

43. Park, H. H. Structure of TRAF Family: Current Understanding of Receptor Recognition. Front. Immunol. 9, 1999 (2018). 
44. Park, Y. C., Burkitt, V., Villa, A. R., Tong, L., Wu, H. Structural basis for self-association and receptor recognition of human TRAF2. Nature 398, 533-538 (1999).

45. Ye, H., et al. Distinct molecular mechanism for initiating TRAF6 signalling. Nature 418, 443-447 (2002).

46. Wang, L. W., Jiang, S., Gewurz, B. E. Epstein-Barr Virus LMP1-Mediated Oncogenicity. J. Virol. 91, e01718-01716 (2017).

47. Uchida, J., et al. Mimicry of CD40 signals by Epstein-Barr virus LMP1 in B lymphocyte responses. Science 286, 300-303 (1999).

48. Rastelli, J., et al. LMP1 signaling can replace CD40 signaling in B cells in vivo and has unique features of inducing class-switch recombination to IgG1. Blood 111, 1448-1455 (2008).

49. Stunz, L. L., et al. Expression of the cytoplasmic tail of LMP1 in mice induces hyperactivation of B lymphocytes and disordered lymphoid architecture. Immunity 21, 255-266 (2004).

50. Arcipowski, K. M., Stunz, L. L., Bishop, G. A. TRAF6 is a critical regulator of LMP1 functions in vivo. Int. Immunol. 26, 149-158 (2014).

51. Pullen, S. S., Miller, H. G., Everdeen, D. S., Dang, T. T., Crute, J. J., Kehry, M. R. CD40-tumor necrosis factor receptor-associated factor (TRAF) interactions: regulation of CD40 signaling through multiple TRAF binding sites and TRAF hetero-oligomerization. Biochemistry 37, 11836-11845 (1998).

52. Leo, E., et al. Differential requirements for tumor necrosis factor receptor-associated factor family proteins in CD40-mediated induction of NF-kappaB and Jun N-terminal kinase activation. J. Biol. Chem. 274, 22414-22422 (1999).

53. Hostager, B. S. Roles of TRAF6 in CD40 signaling. Immunol. Res. 39, 105-114 (2007).

54. Eliopoulos, A. G., Wang, C. C., Dumitru, C. D., Tsichlis, P. N. Tpl2 transduces CD 40 and TNF signals that activate ERK and regulates IgE induction by CD40. EMBO J. 22, 3855-3864 (2003).

55. Wu, S., et al. LMP1 protein from the Epstein-Barr virus is a structural CD40 decoy in B lymphocytes for binding to TRAF3. J. Biol. Chem. 280, 33620-33626 (2005).

56. Pullen, S. S., Dang, T. T., Crute, J. J., Kehry, M. R. CD40 signaling through tumor necrosis factor receptor-associated factors (TRAFs). Binding site specificity and activation of downstream pathways by distinct TRAFs. J. Biol. Chem. 274, 14246-14254 (1999).

57. Noels, H., et al. A Novel TRAF6 binding site in MALT1 defines distinct mechanisms of NF-kappaB activation by API2middle dotMALT1 fusions. J. Biol. Chem. 282, 10180-10189 (2007).

58. Shi, Z., et al. Structural Insights into mitochondrial antiviral signaling protein (MAVS)-tumor necrosis factor receptor-associated factor 6 (TRAF6) signaling. J. Biol. Chem. 290, 26811-26820 (2015).

59. Moriya, J., et al. Structure-Based Development of a Protein-Protein Interaction Inhibitor Targeting Tumor Necrosis Factor Receptor-Associated Factor 6. J. Med. Chem. 58, 5674-5683 (2015).

60. Kaye, K. M., Izumi, K. M., Mosialos, G., Kieff, E. The Epstein-Barr virus LMP1 cytoplasmic carboxy terminus is essential for B-lymphocyte transformation; fibroblast cocultivation complements a critical function within the terminal 155 residues. J. Virol. 69, 675-683 (1995). 
61. Sommermann, T., et al. Functional interplay of Epstein-Barr virus oncoproteins in a mouse model of B cell lymphomagenesis. Proc. Natl. Acad. Sci. U.S.A. 117, 14421-14432 (2020).

62. Bharti, A. C., Takada, Y., Shishodia, S., Aggarwal, B. B. Evidence that receptor activator of nuclear factor (NF)-kappaB ligand can suppress cell proliferation and induce apoptosis through activation of a NF-kappaB-independent and TRAF6-dependent mechanism. J. Biol. Chem. 279, 6065-6076 (2004).

63. Poblenz, A. T., Jacoby, J. J., Singh, S., Darnay, B. G. Inhibition of RANKL-mediated osteoclast differentiation by selective TRAF6 decoy peptides. Biochem. Biophys. Res. Commun. 359, 510-515 (2007).

64. Ikeda, O., et al. BS69 cooperates with TRAF3 in the regulation of Epstein-Barr virus-derived LMP1/CTAR1-induced NF-kappaB activation. FEBS Lett. 584, 865-872 (2010).

65. Ikeda, O., et al. BS69 negatively regulates the canonical NF-kappaB activation induced by EpsteinBarr virus-derived LMP1. FEBS Lett. 583, 1567-1574 (2009).

66. Yin, Q., et al. E2 interaction and dimerization in the crystal structure of TRAF6. Nat. Struct. Mol. Biol. $16,658-666$ (2009).

67. Das, A., Middleton, A. J., Padala, P., Ledgerwood, E. C., Mace, P. D., Day, C. L. The Structure and Ubiquitin Binding Properties of TRAF RING Heterodimers. J. Mol. Biol. 433, 166844 (2021).

68. Floettmann, J. E., Eliopoulos, A. G., Jones, M., Young, L. S., Rowe, M. Epstein-Barr virus latent membrane protein-1 (LMP1) signalling is distinct from CD40 and involves physical cooperation of its two C-terminus functional regions. Oncogene 17, 2383-2392 (1998).

69. Xie, P., Bishop, G. A. Roles of TNF receptor-associated factor 3 in signaling to $B$ lymphocytes by carboxyl-terminal activating regions 1 and 2 of the EBV-encoded oncoprotein latent membrane protein 1. J. Immunol. 173, 5546-5555 (2004).

70. Cahir-McFarland, E. D., et al. Role of NF-kappa B in cell survival and transcription of latent membrane protein 1-expressing or Epstein-Barr virus latency III-infected cells. J. Virol. 78, 4108-4119 (2004).

71. Miyake, A., et al. Induction of apoptosis in Epstein-Barr virus-infected B-lymphocytes by the NFkappaB inhibitor DHMEQ. Microbes Infect. 10, 748-756 (2008).

72. Liu, Z., Chen, H., Wold, E. A., Zhou, J. Small-Molecule Inhibitors of Protein-Protein Interactions. In: Comprehensive Medicinal Chemsitry, 3rd Edition (eds. Chackalamannil, S., Rotella, D., Ward, E.S.). Elsevier (2017).

73. de Jong, S. J., Albrecht, J. C., Giehler, F., Kieser, A., Sticht, H., Biesinger, B. Noncanonical NF-kappaB Activation by the Oncoprotein Tio Occurs Through a Nonconserved TRAF3-Binding Motif. Sci. Signal. 6, ra27 (2013).

74. Morita, S., Kojima, T., Kitamura, T. Plat-E: an efficient and stable system for transient packaging of retroviruses. Gene Ther. 7, 1063-1066 (2000).

75. Schwieger, M., Lohler, J., Friel, J., Scheller, M., Horak, I., Stocking, C. AML1-ETO inhibits maturation of multiple lymphohematopoietic lineages and induces myeloblast transformation in synergy with ICSBP deficiency. J. Exp. Med. 196, 1227-1240 (2002). 
76. Lomaga, M. A., et al. TRAF6 deficiency results in osteopetrosis and defective interleukin-1, CD40, and LPS signaling. Genes Dev. 13, 1015-1024 (1999).

77. Kavathas, P., Bach, F. H., DeMars, R. Gamma ray-induced loss of expression of HLA and glyoxalase I alleles in lymphoblastoid cells. Proc. Natl. Acad. Sci. U.S.A. 77, 4251-4255 (1980).

78. Lenoir, G. M., Vuillaume, M., Bonnardel, C. The use of lymphomatous and lymphoblastoid cell lines in the study of Burkitt's lymphoma. IARC Sci. Publ., 309-318 (1985).

79. Meyer, M., de Angelis, M. H., Wurst, W., Kuhn, R. Gene targeting by homologous recombination in mouse zygotes mediated by zinc-finger nucleases. Proc. Natl. Acad. Sci. U.S.A. 107, 15022-15026 (2010).

80. Wu, Y., et al. Correction of a genetic disease in mouse via use of CRISPR-Cas9. Cell Stem Cell 13, 659-662 (2013).

81. Studier, F. W. Protein production by auto-induction in high density shaking cultures. Protein Expr. Purif. 41, 207-234 (2005).

82. Delaglio, F., Grzesiek, S., Vuister, G. W., Zhu, G., Pfeifer, J., Bax, A. NMRPipe: a multidimensional spectral processing system based on UNIX pipes. J. Biomol. NMR 6, 277-293 (1995).

83. Vranken, W. F., et al. The CCPN data model for NMR spectroscopy: development of a software pipeline. Proteins 59, 687-696 (2005).

\section{Figures}




\section{Figure 1}

A

His-TRAFs

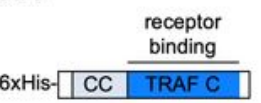

GST-LMP1
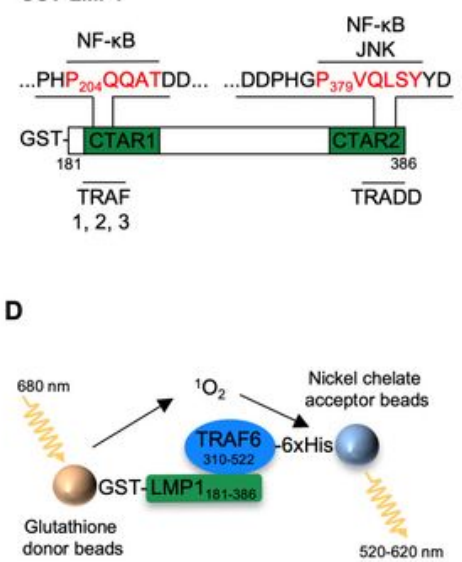

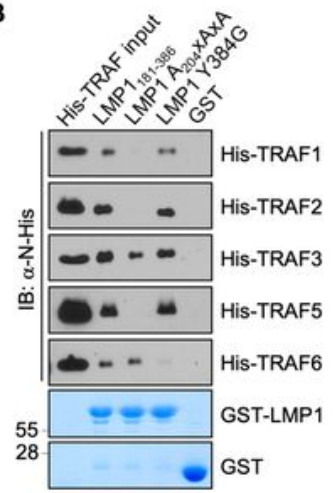

E

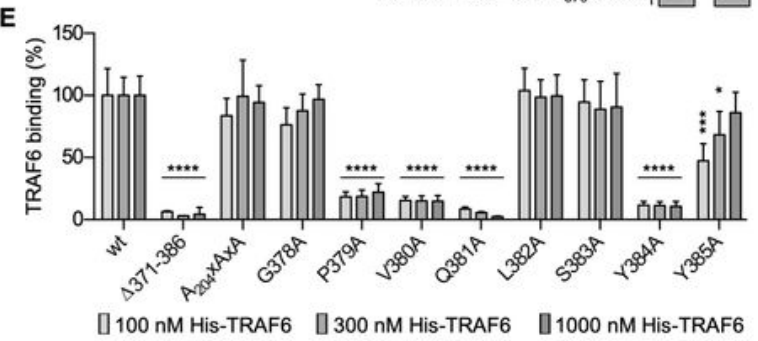

C \# Peptide mutation H-T6 H-T2 1 CD40 230-259 2 CD40 230-259 $\mathrm{A}_{250} \times \mathrm{AXA}$ 3 CD40 230-259 $\mathrm{A}_{231} \times \mathrm{AXA}$ 4 CD40 244-273

5 CD40 244-273 $\mathrm{A}_{250} \times \mathrm{AxA}$

6 LMP1 198-227

7 LMP1 198-227 A A $040 \times A \times A$

8 LMP1 371-386

9 LMP1 371-386 $\mathrm{A}_{384} \mathrm{~A}_{385}$

10 LMP1 371-386 $A_{379} \times A \times A$

11 LMP1 357-386

12 LMP1 357-386 A 379 XXXA

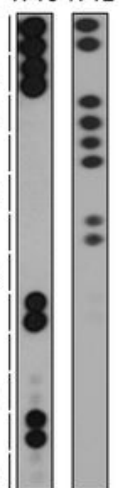

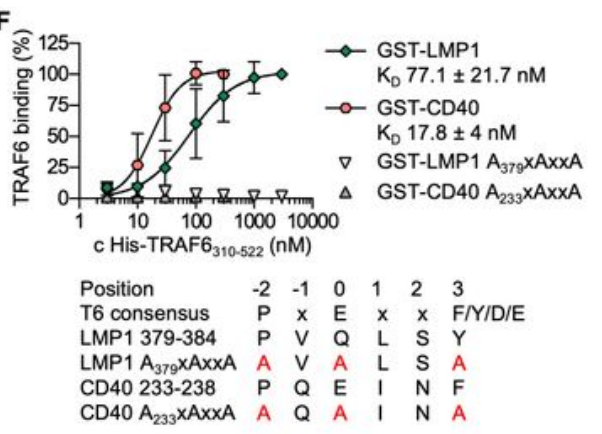

G

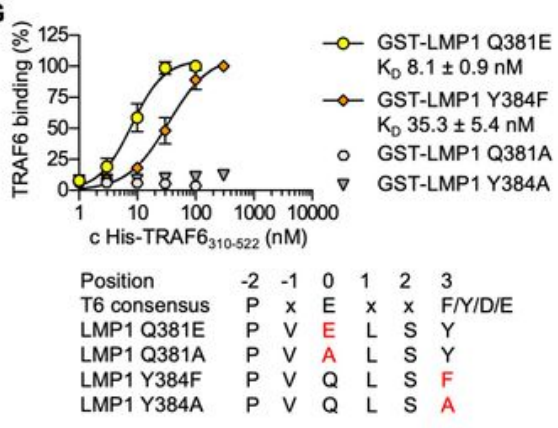

Figure 1

Direct interaction of TRAF6 with the CTAR2 of LMP1.

(A) Schematic depiction of recombinant His-tagged TRAF and GST-fused LMP1 proteins used in this study. CTAR1 and CTAR2 core sequences are highlighted in red. Relevant previously described direct interaction partners are shown. CC, coiled coil. 
(B) TRAF1, 2, 3, and 5 interact with the PxQxT motif of CTAR1, whereas TRAF6 directly binds to the CTAR2 domain. Recombinant His-TRAF proteins were detected via their His-tags on immunoblots (IB) of pulldowns with the indicated GST-LMP1 proteins. Representative results are shown. Number of independent experiments: TRAF1, $n=2 ;$ TRAF2, $n=3$; TRAF3, $n=3$; TRAF5, $n=3$; TRAF6, $n=3$.

(C) Mutation of the CTAR2 sequence $P_{379}$ VQLSY abolishes TRAF6 interaction with LMP1. LMP1-derived peptides and CD40-derived controls were immobilized on membranes in duplicates, and incubated with recombinant His-TRAF6 ${ }_{310-522}$ (H-T6) or His-TRAF2 $311-501$ (H-T2). Peptide binding of TRAF6 or TRAF2 proteins was detected via TRAF-specific antibodies.

(D) Design of the AlphaScreen protein-protein interaction (PPI) mix-and-measure assay established to detect and quantify direct TRAF6 binding to LMP1.

(E) LMP1 residues $P_{379}, V_{380}, Q_{381}$ and $Y_{384}$ are essential for TRAF6 interaction in AlphaScreen PPI assays. Data are mean values \pm SD of three independent experiments. Statistics: two-way ANOVA.

(F) TRAF6 shows a weaker affinity to LMP1 as to CD40. His-TRAF6 ${ }_{310-522}$ AlphaScreen PPI assays with GST-LMP1 $1_{181-386}$ and GST-CD40 $216-277 . \mathrm{K}_{\mathrm{D}}$ values for LMP1 and CD40 are given. Data are mean values \pm SD of three independent experiments. Curve fitting: Prism 6, one-site-specific binding with hill slope.

(G) Conversion of LMP1 amino acids $\mathrm{Q}_{381}$ and $\mathrm{Y}_{384}$ into the cellular TRAF6 binding site consensus increases affinity towards His-TRAF $6_{310-522}$. Data are mean values \pm SD of three independent experiments. Curve fitting: Prism 6, one-site-specific binding with hill slope.

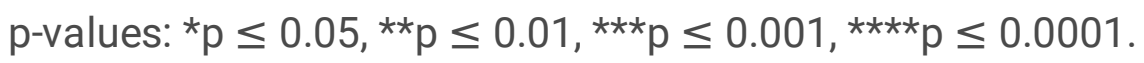




\section{Figure 2}

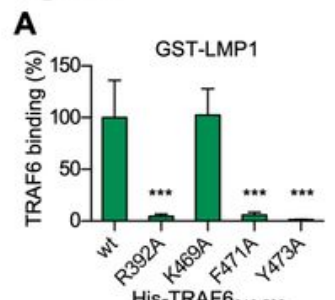

C
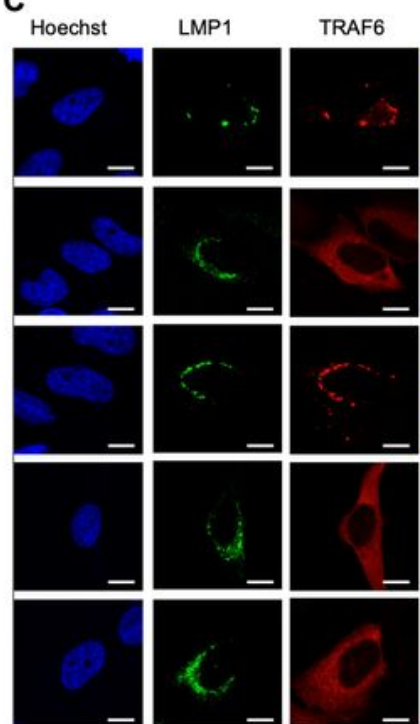

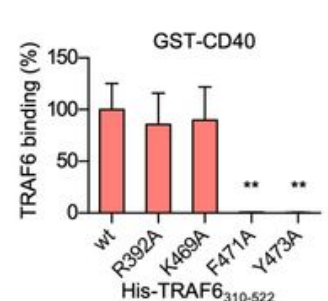

His-TRAF6 ${ }_{310-522}$
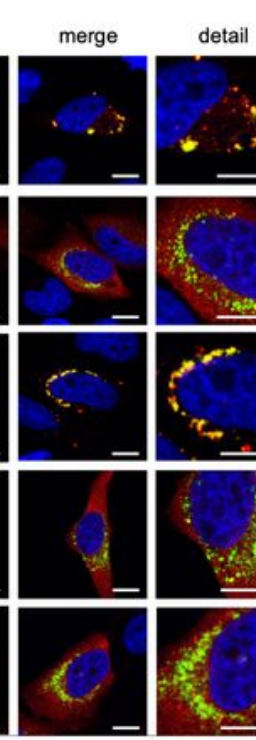

B
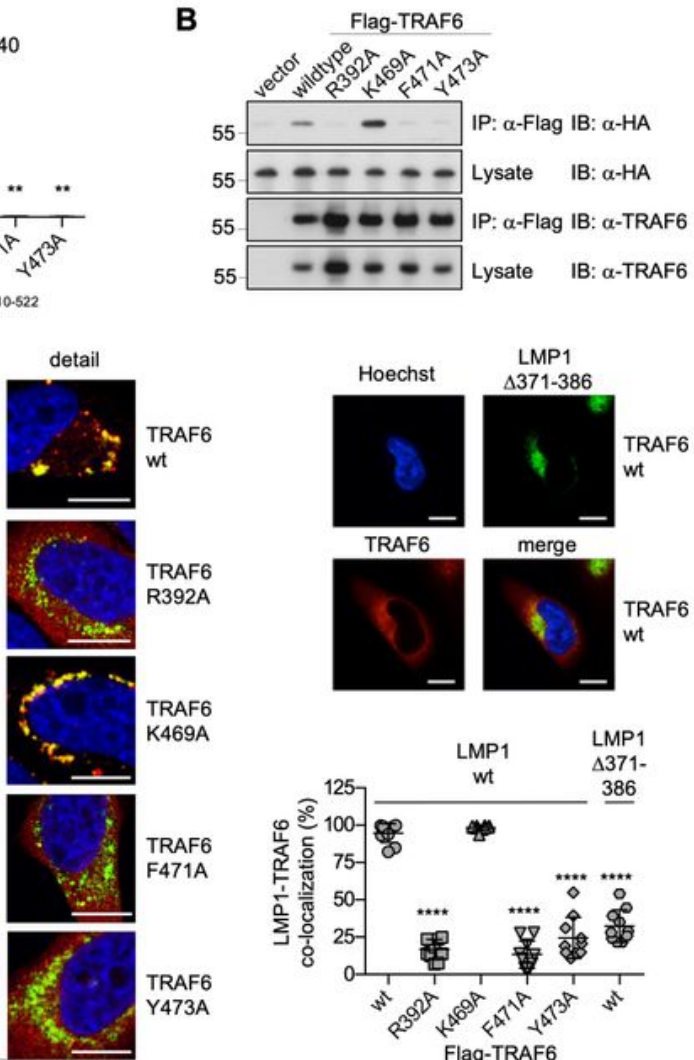
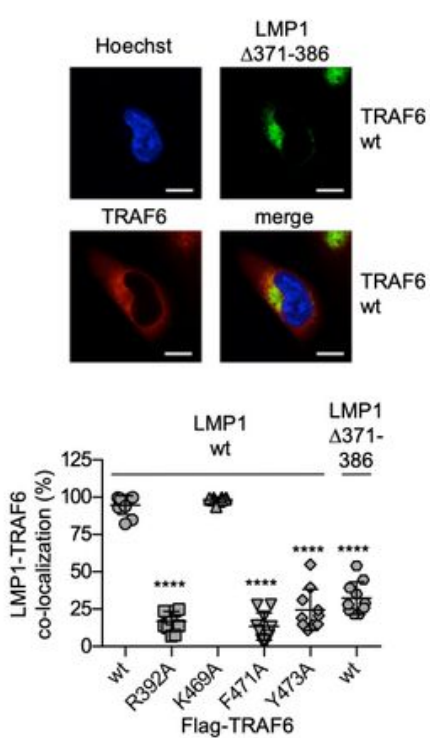

Figure 2

LMP1 binds to the receptor-interacting surface of TRAF6.

(A) Mutations within the receptor-interacting surface of TRAF6 affect binding to LMP1 and CD40 differently. The TRAF6 mutant $\mathrm{R}_{392} \mathrm{~A}$ discriminates between LMP1 and CD40 in AlphaScreen PPI experiments. Data are mean values \pm SD of three independent experiments. Statistics: one-way ANOVA. 
(B) TRAF6 mutants that fail to interact with LMP1 in PPI assays are also unable to bind cellular LMP1. HEK293 cells were transfected with HA-LMP1 and the indicated Flag-TRAF6 mutants. Flag-TRAF6 was immunoprecipitated (IP) via its Flag-tag and co-precipitated HA-LMP1 was detected on immunoblots by an a-HA antibody. One representative result of three independent experiments is shown. For statistical analysis of all experiments see Supplementary Figure 2A.

(C) TRAF6 wildtype and TRAF6 $\mathrm{K}_{469} \mathrm{~A}$ co-localize with wildtype LMP1 clusters in HeLa cells, whereas $R_{392} A, F_{471} A$, and $Y_{473} A$ fail to interact with LMP1 (left panel). TRAF6 recruitment is dependent on amino acids 371 - 386 of LMP1 (right panel). Confocal microscopy images show representative cells of three independent experiments. Quantitative data are mean values \pm SD of ten randomly selected cells per transfection of one representative experiment. Scale: $10 \mu \mathrm{m}$. Statistics: one-way ANOVA.

$p$-values: ${ }^{\star} p \leq 0.05,{ }^{\star \star} p \leq 0.01,{ }^{\star * \star} p \leq 0.001,{ }^{* \star \star *} p \leq 0.0001$. 
Figure 3

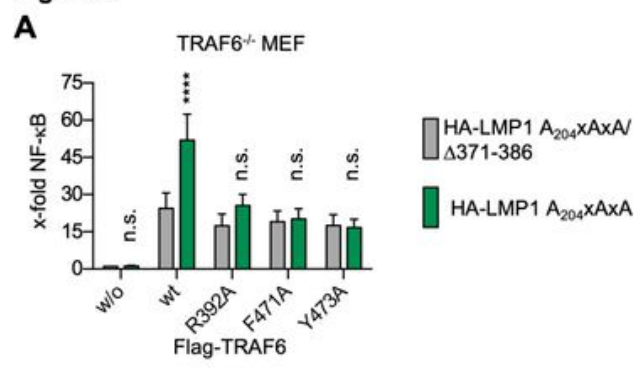

B

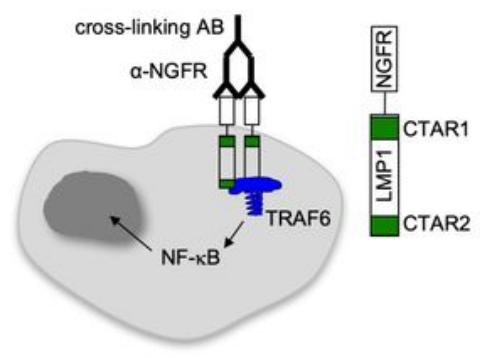

C

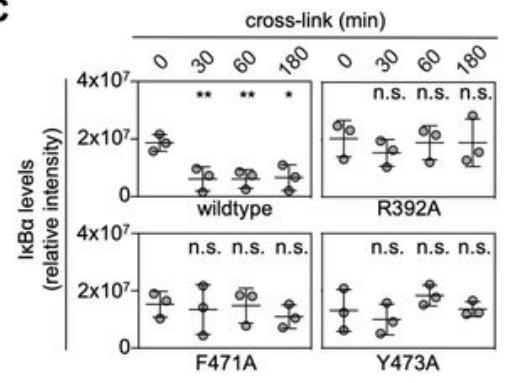

TRAF6"-MEF + NGFR-LMP1

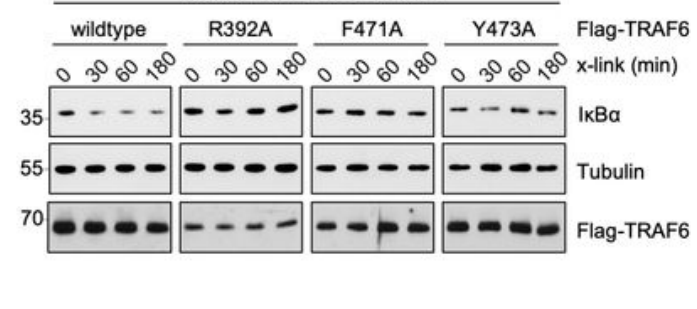

\section{Figure 3}

Direct binding of TRAF6 to LMP1 is essential to activate signaling by CTAR2.

(A) TRAF6 mutants incapable of direct LMP1 binding fail to rescue CTAR2 signaling to NF-KB. Transient NF-KB reporter assays in TRAF6-/- MEFs. CTAR2-specific signaling was induced by the CTAR1 mutant $\mathrm{A}_{204} \mathrm{XAxA}$. The CTAR1/CTAR2 double mutant $\mathrm{A}_{204} \mathrm{XAxA}$ /D371-386 served as inactive null control. TRAF6 
wildtype or mutants were co-transfected as indicated. Data are mean values \pm SD of five independent experiments. Statistics: two-way ANOVA.

(B) NGFR-LMP1 consists of the LMP1 signaling domain and the transmembrane and extracellular domains of p75 NGF receptor. NGFR-LMP1 activity is induced at the cell surface by an a-NGFR primary antibody and subsequent cross-linking with a secondary antibody, allowing time-resolved analysis of LMP1 signaling.

(C) TRAF6 mutants lacking direct LMP1 binding activity are unable to rescue canonical NF-KB activation by NGFR-LMP1 in TRAF6-deficient MEFs. TRAF6-/-MEFs stably expressing NGFR-LMP1 were transduced with Flag-TRAF6 wildtype or the indicated mutants, NGFR-LMP1 activity was induced by antibody crosslinking for the given times, and IкBa levels were analysed by immunoblotting. Representative blots are shown (right). Data are mean values \pm SD of three independent experiments. Statistics (left): one-way ANOVA.

p-values: ${ }^{\star} p \leq 0.05,{ }^{\star \star} p \leq 0.01,{ }^{\star \star \star} p \leq 0.001,{ }^{\star \star \star \star} p \leq 0.0001$, n.s., not significant. 

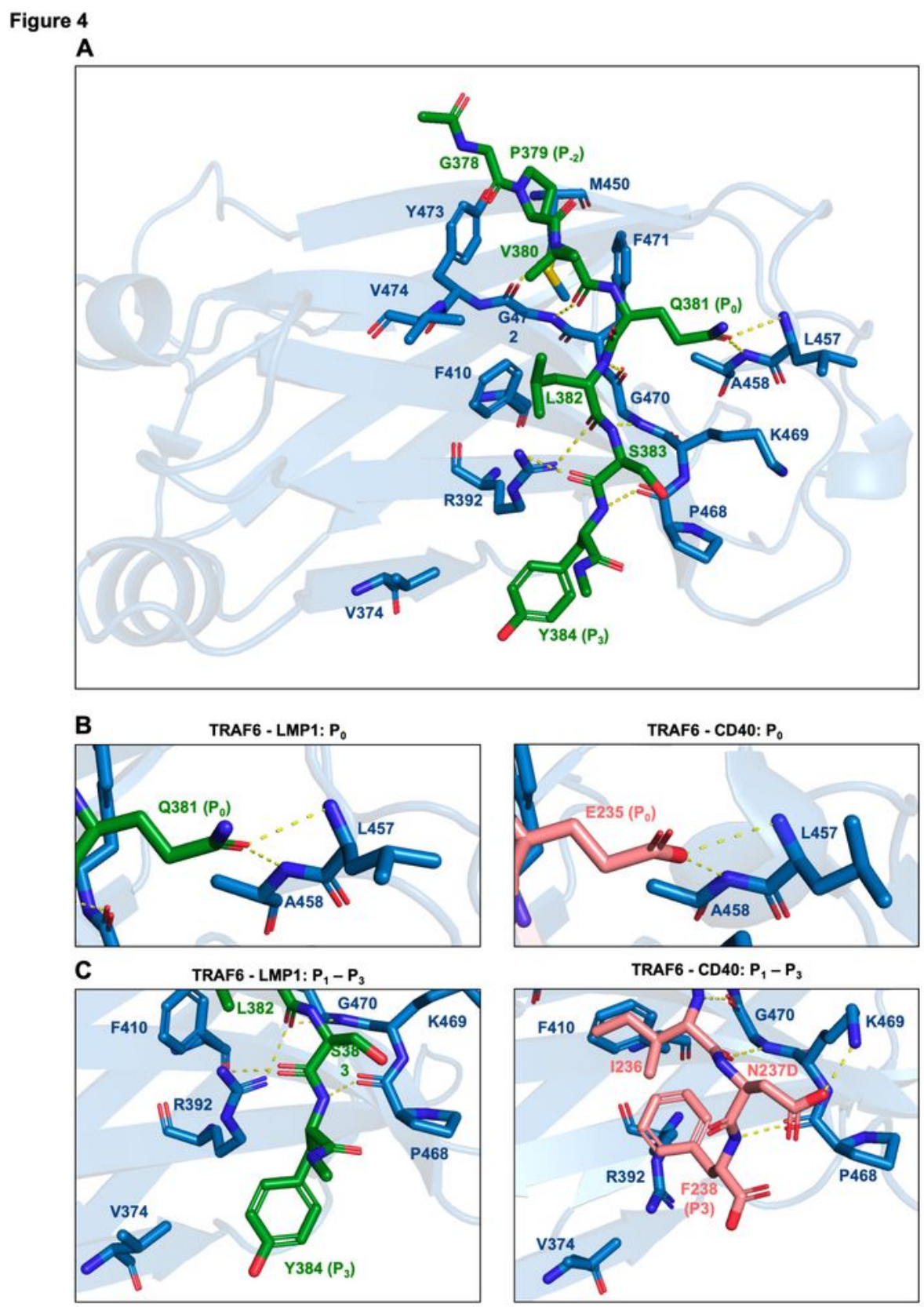

\section{Figure 4}

\section{Molecular model of LMP1 in complex with TRAF6.}

(A) In silico structure of the LMP1 peptide $\mathrm{GP}_{379} \mathrm{VQLSY}_{384}$ (green) bound to the receptor-binding interface of the TRAF domain of TRAF6 (blue). Hydrogen bonds formed between LMP1 and TRAF6 LMP1 are indicated by dashed lines. 
(B) Pose around position $\mathrm{P}_{0}$ of LMP1 (left, in silico model) compared to CD40 (right, based on crystal structure PDB 1 LB6 ${ }^{45}$ ).

(C) Pose around positions $\mathrm{P}_{1}-\mathrm{P}_{3}$ of LMP1 (left, in silico model) compared to CD40 (right, based on PDB 1LB6). $N_{237}$ of CD40 wildtype was mutated to $D_{237}$ to generate PDB $1 L B 6{ }^{45}$. Note the stretched conformation of $\mathrm{Y}_{384}$ at $\mathrm{P}_{3}$ of LMP1 versus the kinked conformation of $\mathrm{F}_{238}$ of CD40.

TRAF6 - blue, LMP1 - green, CD40 - salmon, polar contacts - yellow dashed lines. 

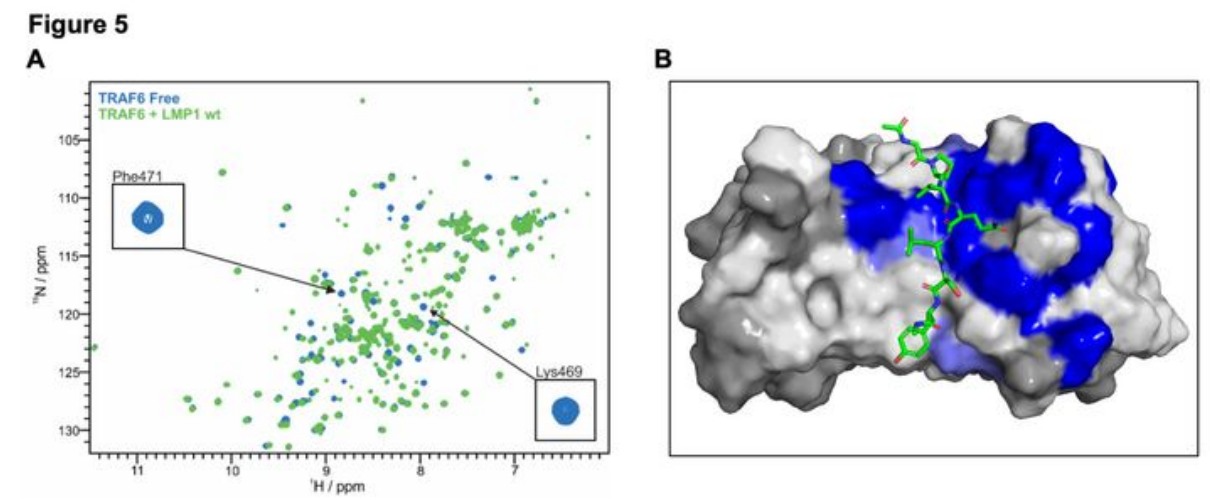

\section{Figure 5}

Binding of LMP1 induces intramolecular shifts in TRAF6.

(A) Overlay of the shift patterns of the HSQC NMR spectra of TRAF6 alone (blue) and TRAF6 in complex with the LMP1 peptide $\mathrm{G}_{378}$ PVQLSYYD (green). Peaks of $\mathrm{F}_{471}$ and $\mathrm{K}_{469}$ are highlighted. 
(B) Chemical shifts induced by LMP1 peptide binding at the surface of TRAF6 are highlighted in the in silico LMP1-TRAF6 structure described in Figure 4. TRAF6 residues showing strong shifts upon LMP1 binding $(>0.05)$ are indicated in dark blue, residues showing weaker shifts $(0.025-0.05)$ in light blue. Residues without shift upon LMP1 binding are indicated in dark gray. TRAF6 residues without an assignment to a specific NMR peak are shown in light grey. For the latter residues no NMR-based conclusion is possible regarding their shifting upon LMP1 binding. 
Figure 6
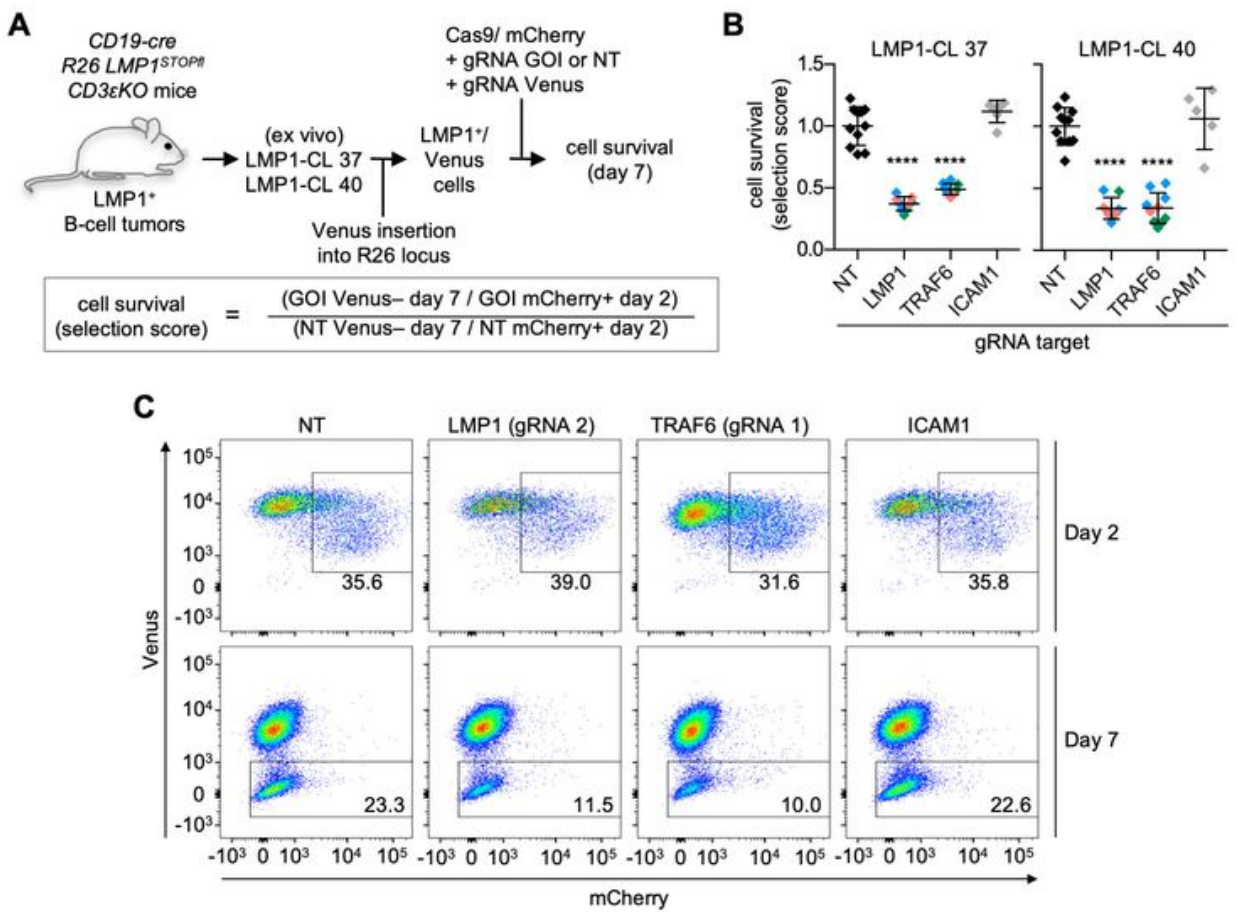

Figure 6

TRAF6 is essential for LMP1-induced B cell lymphoma survival.

(A) Experimental set-up. LMP1-dependent mouse B cell lymphomas LMP1-CL 37 and 40 were derived from CD19-cre;R26LMP1 ${ }^{\text {STOPfl. }}$ :CD3 $\varepsilon^{\mathrm{KO}}$ mice. Venus marker expression was achieved by CRISPR/Cas9mediated insertion of Venus into the Rosa26 locus. Subsequently, the cells were simultaneously 
electroporated with two pX330-mCherry-CAS9 vectors, the first construct expressing a gRNA targeting Venus, the second construct expressing either one out of three gRNAs targeting the genes of interest (GOI) LMP1 and TRAF6, or one gRNA targeting ICAM1, or a non-targeting gRNA (NT). Both vectors also expressed mCherry to monitor transfection efficiency. Cell survival was determined by flow cytometry at day 7 post transfection as selection score: percentage of Venus-negative GOI gRNA versus NT gRNA cells, normalised for transfection efficiencies (mCherry-positive cells at day 2).

(B) The ex vivo knockout of TRAF6 in two LMP1-dependent B cell lymphomas inhibits survival as efficient as the knockout of LMP1 itself. Number of experiments: NT gRNA, $n=11$ (black); LMP1 gRNA \#1, $n=3$ (green); LMP1 gRNA \#2, n=3 (blue); LMP1 gRNA \#3, n=3 (salmon); TRAF6 gRNA \#1, n=4 (green); TRAF6 gRNA \#2, n=4 (blue); TRAF6 gRNA \#3, n=2 (salmon); ICAM1 gRNA, n=5 (grey). Statistics: one-way ANOVA. p-values: $* \star \star \star p ~ \leq 0.0001$.

(C) FACS profiles of one representative experiment with lymphoma LMP1-CL 37. 


\section{Figure 7}
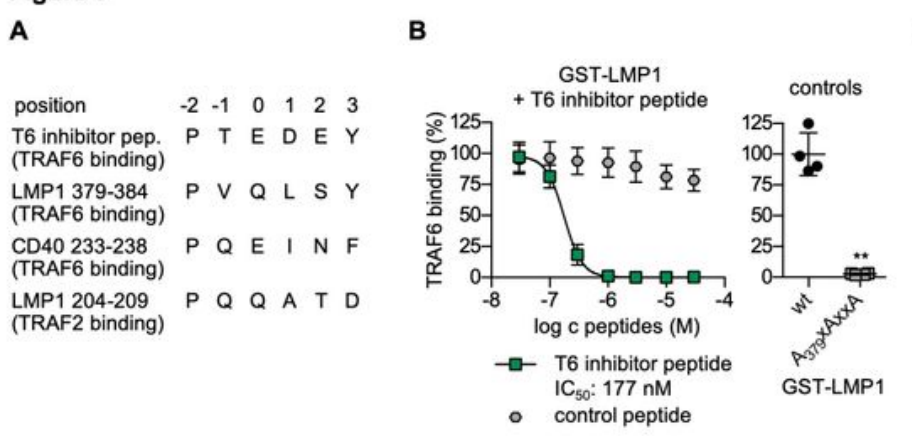

C
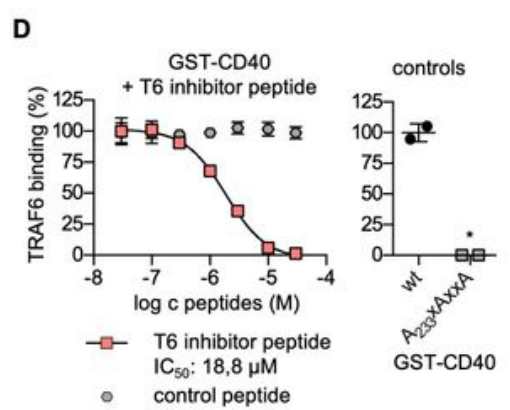

E
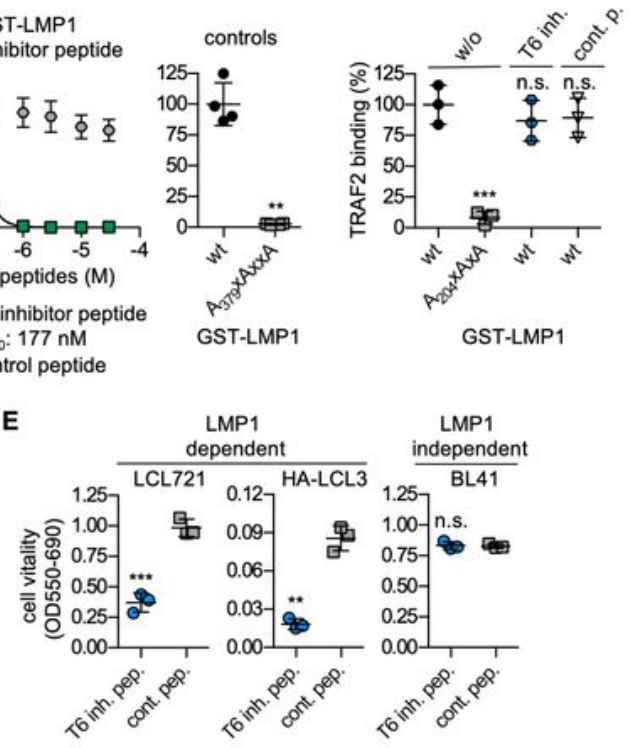

\section{Figure 7}

Disruption of LMP1-TRAF6 interaction inhibits cell survival of EBV-transformed human B cells.

(A) Alignment of the TRAF6-interacting sequence of the TRAF6 inhibitor peptide DRQIKIWFQNRRMKWKKRKIPTEDEY with the TRAF6-binding sequences of LMP1 and CD40, as well as the TRAF2-binding sequence of LMP1. 
(B) TRAF6 binding to LMP1 is efficiently inhibited by the TRAF6 inhibitor peptide. Left, AlphaScreen PPI assay-based dose-response curve of TRAF6 inhibitor peptide (green) with recombinant GST-LMP1 $1_{181-386}$ and His-TRAF6 ${ }_{310-522}$. The Antennapedia leader peptide DRQIKIWFQNRRMKWKK served as negative control (grey). Right, TRAF6 binding is absent for LMP1 null mutant $A_{379} \times A x x A$. Data are mean values \pm SD of four independent experiments. Dose-response curve fitting: 4-parameter fit. Statistics for controls (right): paired T-test.

(C) The TRAF6 inhibitor peptide does not inhibit TRAF2 binding to LMP1. GST-LMP1 and His-TRAF2 311 501 were incubated in the presence of $30 \mu \mathrm{M}$ of TRAF6 inhibitor or control peptide in AlphaScreen PPI experiments. Data are mean values \pm SD of three independent experiments. Statistics: one-way ANOVA.

(D) Peptide-mediated inhibition of TRAF6 binding to CD40 is less effective as compared to LMP1. Left, AlphaScreen PPI experiments with GST-CD40 and His-TRAF6 $310-522$. Right, TRAF6 binding to the CD40 null mutant $A_{233} \times A x x A$. Data are mean values $\pm S D$ of two independent experiments. Dose-response curve fitting: 4-parameter fit. Statistics for controls: paired T-test.

(E) Inhibition of LMP1-dependent cell proliferation of LCLs by the TRAF6 inhibitor peptide. Cells were incubated for three days in the presence of $100 \mu \mathrm{M}$ of TRAF6 inhibitor peptide or control peptide as indicated. Data are mean values \pm SD of biological triplicates. Statistics: unpaired T-test.

p-values: ${ }^{\star} p \leq 0.05,{ }^{\star \star} p \leq 0.01,{ }^{* \star} p \leq 0.001$, n.s., not significant.

\section{Supplementary Files}

This is a list of supplementary files associated with this preprint. Click to download.

- Giehleretalsupplementaryinformation.docx 